\title{
Advanced model for predicting the fire response of concrete filled tubular columns
}

\author{
Ana Espinos, Manuel L. Romero*, Antonio Hospitaler \\ Instituto de Ciencia y Tecnología del Hormigón (ICITECH) \\ Universidad Politécnica de Valencia, Camino de Vera s/n, 46022 Valencia (Spain) \\ *mromero@mes.upv.es
}

\begin{abstract}
In this work, a nonlinear finite element three-dimensional model is presented and validated in order to study the behaviour of axially loaded concrete filled tubular (CFT) columns with circular cross-section exposed to fire. A realistic sequentially coupled nonlinear thermal-stress analysis is conducted for a series of columns available in the literature. The model is validated by comparing the simulation results with the real fire resistance tests. By means of this model, and extensive sensitivity analysis is performed over a wide range of aspects concerning the finite element modelling of the problem under study, including new key factors not studied previously. Based on this sensitivity analysis several modelling recommendations are given in this paper, which will be useful for future research work. The validated numerical model is furthermore employed to study and discuss the Eurocode 4 Part 1-2 simple calculation model, which is deeply analysed in this paper.
\end{abstract}

Keywords: Fire resistance; Concrete filled tubular column; Finite element analysis; Simple calculation model 


\section{NOTATION}

(cal) Concrete with calcareous aggregates

CFT Concrete filled tube

$D$

Diameter of the column

$e$

Loading eccentricity

$\mathrm{EC} 2$

Eurocode 2 Part 1-2 (EN 1992-1-2)

EC3

Eurocode 3 Part 1-2 (EN 1993-1-2)

EC4

Eurocode 4 Part 1-2 (EN 1994-1-2)

F-F

Fixed-fixed supporting conditions

FEM Finite element modelling

FRR Fire resistance rating

$f_{c}$

Compressive cylinder strength of concrete at room temperature (test date)

$f_{s}$

Yield strength of reinforcing steel at room temperature

$f_{y}$

Yield strength of structural steel at room temperature

HSC

High strength concrete

$h_{j}$

Thermal gap conductance

$L \quad$ Length of the column

NSC Normal strength concrete

$N$

Test load

$N_{R d} \quad$ Resistance of the column in axial compression at room temperature

P-P Pinned-pinned supporting conditions

$q$

Heat flux

(sil) Concrete with siliceous aggregates

Temperature

$t \quad$ Thickness of the steel tube

$\alpha_{c} \quad$ Concrete thermal expansion coefficient

$\alpha_{s} \quad$ Steel thermal expansion coefficient

$\delta_{\max } \quad$ Maximum axial displacement

$\mu=N / N_{R d} \quad$ Axial load level

$\xi \quad$ Relative error 


\section{INTRODUCTION}

In the last years, concrete filled tubular columns have become popular among designers and structural engineers, due to a series of highly appreciated advantages: high load-bearing capacity, high seismic resistance, attractive appearance, reduced cross-section, fast construction technology and high fire resistance without external protection. Due to the heat sink effect of the concrete infill that delays the rise of temperatures in the cross-section and the shield effect of the steel tube protecting the concrete core from direct exposure and retaining its integrity, CFT columns can reach high fire resistance times without external fire protection [25]. Nevertheless, in fire situation the degradation of the material properties gives rise to an extremely nonlinear behaviour of these columns, which makes it difficult to predict their failure. In fact, the analytical methods [19] developed in this field are not able to predict accurately the fire response of CFT columns, reason why it is necessary to resort to numerical models. Up to now, a large number of numerical simulations have been conducted worldwide [10], [14], [21], [23], [27], nevertheless some important features need to be included in the model in order to obtain a more realistic representation of the fire behaviour of this type of composite columns. Relevant aspects such as the thermal conductance and the friction model at the steel-concrete interface, the thermal expansion coefficients of steel and concrete or the type of finite element employed to model the reinforcing bars must be carefully taken into account.

Some sectional numerical models [23] have been used to predict the fire behaviour of CFT columns, obtaining quite satisfactory results. Nevertheless, these models were not able to represent the complex local effects and contact mechanisms that take place in a real fire situation. Therefore, if the real behaviour of the columns in fire wants to be studied in depth, a three-dimensional model is needed. 
With that aim, Ding and Wang [10] presented an advanced three-dimensional model for circular and square CFT columns in fire. They included some important features which had often been neglected by other researchers (i.e. the thermal resistance at the steel-concrete interface) and obtained very satisfactory results in fire resistance rating, although the overall response of the column measured in terms of axial displacement along time could be improved. This will be one of the objectives of this paper, not only to obtain an accurate estimation of the fire resistance time, but also to capture with precision the whole response of the column along the fire exposure time.

Hong and Varma [14] also developed an advanced three-dimensional model for predicting the standard fire behaviour of square CFT columns. Nevertheless, these authors assumed no heat loss at the steel-concrete boundary, aspect that might have produced important deviations in their numerical predictions. Again the complete time response of the column in fire could not be captured and only a quantitative estimation of the fire resistance rating was obtained.

In this work, a three-dimensional nonlinear finite element model was developed in order to study the real fire behaviour of CFT columns, in such a way that the whole response during the fire exposure time is obtained with precision. This model included a wide range of realistic and innovative considerations that have not been taken into account by other researchers. One of the novelties of the model presented here is the incorporation of the temperature dependent formulation of the interface thermal conductance proposed by Ghojel [12], which gives a very realistic prediction of the cross-sectional temperature field.

The nonlinear finite element analysis package ABAQUS [1] was chosen to carry out this research, in order to take advantage of the experience gained by the authors in previous work with this tool, which was used to study the buckling behaviour of CFT columns at room temperature, obtaining very satisfactory results. 
The numerical model presented in this paper was validated by comparing the simulation results with experimental fire tests carried out by other researchers and available in the literature [9], [13], [16], [18], showing good agreement with the tests both in fire resistance rating and maximum axial displacement during the whole fire exposure time. The values adopted for the main variables of the problem were a result of an extensive sensitivity analysis conducted in this research, which gives important modelling recommendations for future work. Aspects like the friction model and gap thermal conductance at the steel-concrete interface, the initial geometric imperfection, the mechanical and thermal expansion models of the materials at elevated temperatures, the concrete moisture and density or the rebar element type are deeply analysed in the sensitivity analysis presented here.

The aim of this work is to understand and represent as much close to reality as possible the behaviour of axially loaded CFT columns in fire situation. Although the model presented in this paper was developed for normal strength concrete filling, the range of the "medium" strengths (that is, concrete strengths between 40 and $50 \mathrm{MPa}$ ) was also explored. It was found that complex phenomena arise when reaching these medium strengths, so a more advanced thermo-hydro-mechanical model capable to capture the occurrence of spalling is needed in order to predict accurately the fire response of medium and high strength CFT columns. In fact, other authors [23] found the same errors in their predictions when incorporating the high strength concrete filling to the model and attributed this divergence in the results to the local effects that occur in HSC-filled hollow steel columns when there is no reinforcement.

By means of the validated model, the provisions of Eurocode 4 Part 1-2 will be discussed in this paper. Firstly, the influence of the cross-sectional temperature distribution employed as the first step for calculating the design axial buckling load will be studied. Secondly, the effect of the end conditions and the relative slenderness of the column will be analysed. 


\section{NUMERICAL MODEL}

\subsection{Geometry and finite element mesh of the model}

A three-dimensional numerical model for simulating the fire behaviour of concrete filled circular steel hollow section columns was developed employing the general purpose nonlinear finite element analysis package ABAQUS [1]. The main parameters of the model were the column length $(L)$, the external diameter $(D)$, the steel tube thickness $(t)$, the loading eccentricity (e), the supporting conditions, the axial load level $(\mu)$ and the thermal and mechanical material properties. It consisted of three parts: the concrete core, the steel tube and the loading plate. Due to symmetry on both the geometry and the boundary conditions, only a quarter of the column was modelled, for those specimens with pinned-pinned or fixed-fixed end conditions. For the pinned-fixed columns, the whole length was required due to the loss of symmetry on the boundary conditions, and therefore the columns were modelled with their whole length and half section.

The loading plate was modelled as a perfectly elastic part and through this element the applied axial load was transmitted to both the concrete core and the steel tube.

The model was meshed with three-dimensional eight-node solid elements for both the steel tube and the concrete core, and two-node elements for the reinforcing bars. The mesh density was controlled to have a maximum element size of $2 \mathrm{~cm}$, what proved to be sufficient to predict with enough accuracy the thermal and mechanical behaviour of the CFT columns under fire. Fig. 1 shows the finite element mesh for one of the CFT column specimens analysed. 


\subsection{Material properties at elevated temperatures}

The numerical model took into account the temperature dependent thermal and mechanical properties of the materials. All the selected values that are presented here will be further discussed in the sensitivity analysis section.

For concrete, the mechanical model developed by Lie [19] was employed, as it showed the more realistic response. It had been previously proved by Hong-Varma [14] that this model was the one that best predicted the behaviour of the concrete infill in CFT columns, which will be confirmed in this research. The implemented concrete mechanical model employed the hyperbolic Drucker-Prager yield surface. The thermal properties for concrete at elevated temperatures were extracted from EN 1992-1-2 [6].

For structural steel, the temperature dependent thermal and mechanical properties recommended in EN 1993-1-2 [7] were adopted. The isotropic multiaxial plasticity model with the Von Mises yield surface was employed.

For the reinforcing steel, the thermal properties were the same that those used for the structural steel, as indicated in EN 1994-1-2 [8]. The strength and deformation properties were obtained by means of the same mathematical model as that of the structural steel, but with the reduction factors recommended in EN 1992-1-2 [6].

The value of the thermal expansion coefficient for concrete recommended by HongVarma [14] was employed: $\alpha_{c}=6 \times 10^{-6}{ }^{\circ} \mathrm{C}^{-1}$. For steel, the temperature dependent values of the thermal expansion coefficient from EN 1993-1-2 [7] were adopted.

The moisture content of the concrete infill was taken into account through a peak value in the specific heat, representing the latent heat of water vaporization. EN 1994-1-2 [8] recommends a peak value of $2020 \mathrm{~J} / \mathrm{kgK}$ for a moisture content of $3 \%$ in concrete weight, and $5600 \mathrm{~J} / \mathrm{kgK}$ for a moisture content of $10 \%$. In this research, the best correlation when 
comparing with tested columns was obtained with a $3 \%$ for the siliceous aggregates specimens, while for the calcareous aggregates specimens the optimum value was a $10 \%$.

\subsection{Initial geometric imperfection of the column}

The proposed numerical model took into account the initial geometric imperfection of the column specimens due to the manufacturing process, which makes them no to be perfectly straight. This initial geometric imperfection of the column specimens was simulated in the model as the first buckling mode shape of the hinged column multiplied by an amplification factor. For this purpose, a previous eigenvalue analysis of the model was conducted over a pinned-pinned column subjected to axial loading. Once the initial shape of the column was

obtained, it was imported to the mechanical model as the starting geometry from which to run the analysis. An amplification factor equal to the maximum imperfection along the length of the column was then applied to the column. The value of L/1000 employed by the majority of researchers for the amplification factor was used. The selection of this value will be discussed in the later sensitivity analysis section.

The deformed shape obtained for each of the column specimens by means of this procedure was employed as the initial geometry for conducting the thermal-mechanical analysis.

\subsection{Analysis procedure}

Two different approaches can be considered when conducting the thermal-mechanical analysis of the model. The first one, more basic and less time-consuming is to perform a sequentially coupled thermal-stress analysis. In this type of analysis, the stress/displacement solution is dependent on the temperature field but there is no inverse dependency. This type of analysis can be run as long as the thermal resistance at the steel-concrete boundary is thought 
to be independent from the gap clearance. The average computation time of this approach is between two and three hours, depending on the output variables requested.

The second approach, highly non-linear and thus more computationally costly, is to perform a fully coupled thermal-stress analysis, assuming that the thermal resistance on the steel-concrete boundary is a function of the gap clearance. The gap conductance will decrease as the two contacting surfaces progressively separate from each other due to the thermal expansion differentials. In that case, the thermal and mechanical solutions affect each other strongly and the stress/displacement and temperature fields must be solved simultaneously. This approach required several days of computing time and generated many convergence problems.

Because of the high computing time requirements of the second approach, a sequentially coupled thermal-stress analysis was designed for this research. Therefore, two different models were needed: a heat transfer model and a mechanical model. The analysis was performed by first conducting a pure heat transfer analysis for computing the temperature field and afterwards a stress/deformation analysis for calculating the structural response. Nodal temperatures were stored as a function of time in the heat transfer analysis results and then read into the stress analysis as a predefined field.

Having obtained accurate enough results through a simple sequentially coupled thermalstress analysis, as it will be demonstrated later on in the validation section, it can be concluded that there is no need to perform a fully coupled analysis, which is highly timeconsuming and in most occasions leads to convergence problems.

\subsection{Thermal analysis}

A nonlinear heat transfer analysis was conducted for each of the column specimens under study. A finite element formulation of the basic energy balance equation together with the Fourier law, which governs the heat conduction, was employed. 
For conducting the thermal analysis, the standard ISO-834 [15] or ASTM-E119 [4] fire curve, depending on the specimen studied, was applied to the exposed surface of the CFT column specimens as a thermal load, through the convection and radiation heat transfer mechanisms. In those cases where the fire curve applied at the test deviated from the reference, the real furnace temperature-time curve reported in the literature was used, since this can be an important source of error when validating the model.

The values recommended in EN 1991-1-2 [5] were adopted for the governing parameters of the heat transfer problem:

- Coefficient of convective heat transfer at the exposed surface: $h=25 \mathrm{~W} / \mathrm{m}^{2} \mathrm{~K}$

- Configuration factor for radiation at the exposed surface: $\Phi=1$

- Stephan-Boltzmann constant: $\sigma=5.67 \cdot 10^{-8} \mathrm{~W} / \mathrm{m}^{2} \mathrm{~K}^{4}$

- Emissivity of the exposed surface: $\varepsilon_{m}=0.7$

- Emissivity of the fire: $\varepsilon_{f}=1$

- Initial temperature: $T_{0}=20^{\circ} \mathrm{C}$

The three-dimensional eight-node heat transfer solid element with nodal temperature degree of freedom DC3D8 was used to mesh the thermal model. The longitudinal steel reinforcing bars for the reinforced specimens were modelled by means of two-node heat transfer links DC1D2.

The results from the nonlinear heat transfer analysis consisted of the temperature-time curves for all the nodes within the three-dimensional model, which were subsequently applied as a thermal loading to the mechanical model.

\subsection{Structural analysis}

A nonlinear stress analysis was afterwards conducted using the same FEM package, accounting for the nodal temperature-time curves previously calculated in the thermal model. 
The finite element meshes and the node numbering were exactly the same as those used in the thermal analysis model.

The three-dimensional eight-node solid element C3D8R with reduced integration was used to mesh the concrete infill and the steel tube. The longitudinal steel bars for the reinforced specimens were modelled by means of two-node T3D2 truss elements with both nodes tied to their corresponding concrete nodes.

The choice of the relevant properties of the mechanical model, such as the constitutive laws at elevated temperatures, the values of the thermal expansion coefficient for both concrete and steel, the initial imperfection of the column specimens or the frictional contact at the steel-concrete interface will be discussed in depth in the sensitivity analysis section.

\subsection{Thermal and mechanical contact at the steel-concrete interface}

The thermal resistance at the boundary between the steel tube and the concrete core was modelled by employing a constant value of $200 \mathrm{~W} / \mathrm{m}^{2} \mathrm{~K}$ for the gap conductance. This is one of the aspects that have traditionally been ignored and that will be deeply studied later on in the sensitivity analysis section. Moreover, a radiative heat transfer mechanism was modelled at the steel-concrete interface with emissivities of both steel and concrete surfaces equal to 0.7 and a configuration factor equal to 1 .

The mechanical interaction between the steel tube and concrete infill contacting surfaces was modelled as follows. The normal behaviour employed a "hard point" contact formulation, which allows any pressure value when the surfaces are in contact and transmits no pressure when the surfaces do not contact. The tangent behaviour made use of the Coulomb friction model with a constant friction coefficient of 0.3 , which had previously produced accurate results for the room temperature simulations carried out by the authors. 


\section{VALIDATION OF THE NUMERICAL MODEL}

The three-dimensional numerical model was validated by comparing its results with experimental fire resistance tests of circular CFT columns available in the literature. Most of the columns analysed were tested at the National Research Council of Canada [9], [18]. These specimens were filled with both siliceous and calcareous aggregate concrete, some of them reinforced and subjected to concentric axial load, apart from test C-16 which was eccentrically loaded. All the columns were tested fixed at both ends, except for three of them, tested as pinned-pinned. The total length of the columns was $3810 \mathrm{~mm}$, although only the central $3048 \mathrm{~mm}$ were directly exposed to fire.

Five column specimens from the CIDECT Research Report 15B [13] were also simulated. These specimens were filled with plain concrete, fixed at both ends and subjected to concentric axial load. The length of the columns was $3600 \mathrm{~mm}$.

Finally, the only circular column available at the CIDECT Research Report 15C1/C2 [16] was simulated. This was a bar-reinforced column with a length of $4200 \mathrm{~mm}$ subjected to eccentric axial load and with pinned-fixed end conditions.

The columns analysed have been arranged in two tables for the purpose of establishing a limitation in the scope of the numerical model presented in this paper. Table 1 lists those columns with a concrete filling cylindrical compressive strength lower than $40 \mathrm{MPa}$ (NSC), while Table 2 lists those columns with a concrete filling strength over $40 \mathrm{MPa}$ (as from now "medium strength concrete"). The former will be employed for validating the numerical model and discussing EC4 simple calculation model, while the latter will only be used for studying the possibility of the occurrence of spalling in concrete and therefore establishing the limitations of the numerical model. 
Fig. 2 shows the result of one of the numerical simulations, where the temperature field along the column and its deformed shape after failure can be seen, together with the picture of the fire test.

\subsection{Thermal response}

A first validation step consisted of comparing the evolution of temperature along the fire exposure time in the numerical simulations with the temperatures recorded in the tests at those sectional points where thermocouples were installed. The comparison between measured and calculated temperatures is shown in Fig. 3 for one of the column specimens studied.

A constant value of $200 \mathrm{~W} / \mathrm{m}^{2} \mathrm{~K}$ was employed for the gap conductance at the steelconcrete interface and a moisture content of $3 \%$ or $10 \%$ in concrete weight, depending on the case study was considered. It was found that, in general, concrete with calcareous aggregates retained more humidity than concrete with siliceous aggregates, thus in this research a value of $10 \%$ was considered for the specimens filled with calcareous aggregates, whereas a $3 \%$ value was employed for the siliceous ones.

Employing these moisture values, the overall temperature-time response in the selected points followed accurately the test results, with the exception of the range of temperatures between 100 and $200{ }^{\circ} \mathrm{C}$ in the concrete layers, where the evaporation of moisture occurs. This phenomenon is treated in a simple manner in this research by introducing a peak point in the concrete specific heat formulation, as recommended in EN 1994-1-2 [8]. Nevertheless, if the realistic moisture movement and evaporation within the concrete core wants to be predicted, a more complex hydro-thermal model would be needed.

As mentioned above, some of the tests did not follow as closely as desired the standard fire curve, which introduced some distortions in the fire response of the columns. Thus, the 
real furnace temperature-time curve reported from the fire tests was applied in the simulations, when available.

\subsection{Mechanical response}

The structural behaviour of CFT columns under fire was fully captured with the numerical model presented in this paper and can be easily understood through the example at Fig. 4, which shows the axial displacement-time curve together with the axial force ratio versus time curves for both the steel tube and concrete core. The behaviour of CFT columns in fire can be divided into four stages clearly indicated in the graphic, where the load transfer process from the steel tube to the concrete core can be noticed.

During the first minutes of heating, the steel tube heats up more rapidly and expands faster than concrete (stage 1) since it is directly exposed to fire and has a higher thermal conductivity. Because of this faster axial elongation of the steel tube and the occurrence of slip at the steel-concrete interface, the concrete core loses contact with the loading plate, thus progressively increasing the axial load ratio of steel until the whole applied load is sustained by the steel tube. The steel tube remains fully loaded during a significant period of time until the critical temperature of steel is reached. At this point, the local yielding of the steel tube occurs and it starts to shorten (stage 2), allowing the loading plate to contact the concrete core again. As the column shortens, the steel tube progressively transfers the load to the concrete core (stage 3) and an inversion in the axial force ratio takes place, in such a way that the concrete core becomes the main resistant element of the column, since the steel tube has already lost its load bearing capacity. Because of its low thermal conductivity, the concrete core degrades slowly as temperature advances through the cross-section, until eventually the column fails when concrete loses completely its resistance and stiffness (stage 4).

For each of the columns listed in Table 1, the axial displacement at the top of the column versus the fire exposure time was registered during the simulation, comparing this 
curve with the one obtained in the fire test. Fig. 5 shows the comparison between both curves for two of the column specimens studied.

At this point a comment regarding the pinned-pinned specimens must be done. Despite being designed as hinged at both ends in the experimental tests, the numerical model showed better agreement when the supporting conditions were considered as pinned-fixed. Three different supporting conditions were studied for simulating the pinned-pinned columns and the results for one of the specimens are shown in Fig. 6. It can be seen that the best prediction was obtained modelling the column as pinned-fixed. As it was already found by Renaud et al. in the CIDECT research project 15Q [22], the reason of this behaviour is that in real fire tests the unexposed ends of the column lying outside the furnace retain more stiffness, therefore introducing some rotational restraints to the column. In fact, the deformed shape of these column specimens after the tests suggests employing pinned-fixed supporting conditions when simulating their fire behaviour.

For modelling these specimens as pinned-fixed, the whole length of the column was used, since there is a loss of symmetry on the end conditions, but because of the sectional symmetry only half the section was modelled.

From the axial displacement versus time curves, the fire resistance rating was obtained for each one of the specimens under study. These values are summarized in Table 3 for those specimens with concrete filling resistance under $40 \mathrm{MPa}$. As it can be seen in Fig. 7, most of the values calculated lie in the region of the $15 \%$ error.

The maximum axial displacement was also obtained at the simulations of each of the column specimens studied. Table 3 shows the predicted values and the comparison with the values registered at the fire tests.

It can be noticed that there was more agreement with the test results in those columns with smaller diameters and thus more slender, whereas the massive columns produced more 
error, which may be attributed to the higher contribution of concrete and its more complex failure mechanisms.

\subsection{Medium strength concrete}

A series of columns with concrete filling compressive resistances over $40 \mathrm{MPa}$ were also simulated. These columns must be studied with special care since the spalling starts to be noticeable in their fire behaviour. The values of their measured and computed fire resistance ratings are summarized in Table 4 and plotted in Fig. 8. The maximum axial displacement for each of these column specimens is also listed in Table 4. As it was expected, for most of the specimens analysed in this series, the predicted fire resistance rating was higher than the measured value. This result suggests that a different failure mechanism is likely to be occurring at those column tests with higher concrete strength fillings. In fact, failure in columns C-40, C-41 and C-42 from the National Research Council of Canada [18] was reported to be due to compression instead of overall buckling, which suggests the occurrence of brittle cracking in concrete, effect that the numerical model could not accurately capture at this level of development and therefore explains the divergence between computed and measured failure times.

As reported by Schaumann et al. [23], the cracks initiated at the concrete core by the expansion of the steel tube can be considerable in case there is lack of any reinforcement for high strength concrete specimens. Associated with this effect, the steel hollow section experiences an outward local buckling when the steel section yields at reaching critical temperature. This local buckling of the steel hollow section and crushing of the outer concrete cause the failure in these columns. The micro-cracking effect could not be reproduced in the numerical model and thus explains the high difference encountered for the plain concrete filled specimens in this range of strengths. Nevertheless, the simulations of columns C-48 and C-49 from NRCC [9] are in good agreement with the tests, since the failure mode in these 
cases was overall buckling, micro-cracking being prevented via the reinforcing bars. In the case of CIDECT column 15C-15 [16], despite being bar-reinforced, the loading eccentricity might have magnified the opening of the concrete cracks, leading to the local failure of the column, again not captured by the numerical model proposed here.

The mechanism described above can induce spalling in high strength concrete specimens or even in normal strength concrete ones in case the moisture concentration is too large. Whether the vapour pressure developed is sufficient to cause spalling or not depends not only on the amount of moisture but also on the rate of heating, permeability, porosity and pore distribution in concrete. This is therefore a complicated phenomenon that needs a more complex thermo-hydro-mechanical model for its simulation, which is out of the scope of this paper. This is in fact one of the current research lines of the authors. 


\section{SENSITIVITY ANALYSIS}

An extensive sensitivity analysis was carried out in order to study the influence of the main aspects of the model and to find its optimal values. The aspects studied were the friction model and gap conductance value to be used at the steel-concrete interface, the initial geometric imperfection, the mechanical and thermal expansion models of the materials at elevated temperatures, the concrete moisture and density and the rebar element type. For this purpose, two column specimens from those tested at the National Research Council of Canada [18] were selected, with similar material properties, buckling length and load level but very different $\mathrm{D} / \mathrm{t}$ ratio, so that the study can be valid for CFT columns with both elevated and reduced steel contribution. These column specimens are coded as C-04 and C-05 and their properties collected in Table 1 . The influence of the rebar element type was studied by means of column C-48 from NRCC [9].

\subsection{Steel-concrete interface friction model}

Three options were studied for the steel-concrete frictional interaction: the first option used the classical Coulomb friction model, the second option assumed a full slip between the steel tube and the concrete core (frictionless contact) and the third option considered the existence of a full bond at the steel-concrete interface (rough contact).

The full bond model deviated excessively from the real behaviour of the column, as it can be seen in Fig. 9. The Coulomb friction model and full slip model produced exactly the same results, therefore it can be confirmed that a full slip occurs at the steel-concrete interface in fire situation, since the different thermal expansions cause the separation of the steel tube from the concrete core at elevated temperatures.

To further confirm this fact, different values of the friction coefficient in the Coulomb model were studied, ranging from 0.2 to 0.8 , no difference being obtained in the overall fire 
response. It can be therefore inferred that the value of the friction coefficient at the steelconcrete interface does not have any influence to the column fire behaviour, as the steel tube and concrete core slide relative to each other in fire situation, and thus a frictionless model can be adopted.

\subsection{Gap thermal conductance}

Existing mathematical models for the prediction of the temperature field in concretefilled steel tubular columns [19] do not take into account the resistance to heat flow at the steel-concrete interface, resulting in a significant disagreement between measured and predicted temperatures. This resistance to heat flow is known as the contact thermal resistance and is usually expressed in terms of a joint contact conductance $h_{j}$, defined in terms of Newton's law of cooling:

$$
q=h_{j} \cdot \Delta T
$$

As discussed in 2.4 , the thermal conductance across the steel-concrete interface can be considered either dependent or independent on the gap clearance. In the first case, a fully coupled thermal-stress analysis is required. That is a more realistic approach but requires excessive computational time. Nevertheless, conducting a sequentially coupled thermal-stress analysis assuming the gap conductance to be uncoupled from the clearance produces accurate enough results in a more permissible level of calculation times.

Another aspect to take into account is the dependence of the gap conductance with temperature. In a first approach, a constant value of $h_{j}=200 \mathrm{~W} / \mathrm{m}^{2} \mathrm{~K}$ for the gap conductance was employed, as recommended by Ding-Wang [10]. In a second approach, the interfacial thermal conductance was expressed as a function of temperature as suggested by Ghojel [12], adopting the following correlation proposed by the author for loaded circular steel tubes filled with plain or bar-reinforced concrete: 


$$
h_{j}=160.5-63.8 \cdot \exp \left(-339.9 \cdot T^{-1.4}\right) \mathrm{W} / \mathrm{m}^{2} K
$$

where $T$ is the temperature in degrees Celsius.

The third approach considered the existence of a perfect thermal contact at the steelconcrete interface, that is, the temperature at the contacting surfaces of steel and concrete is the same.

Fig. 10 shows the comparison for the evolution of temperature at significant points of the cross-section under the three approaches studied, where it can be clearly seen that the perfect contact approach overestimates the temperature field. As it can be appreciated in Fig. 11, the model proposed by Ghojel produced the better estimations in failure time, although adopting a constant value of $h_{j}=200 \mathrm{~W} / \mathrm{m}^{2} \mathrm{~K}$ produced acceptable results as well. Assuming that no thermal resistance occurs at the steel-concrete interface is not so realistic and gives very conservative estimations, since the temperature field is moved forward.

\subsection{Initial geometric imperfection}

In order to represent the initial geometric imperfection of the columns, the deformed shape of the pinned-pinned column first buckling mode was obtained, and afterwards amplified by means of an imperfection factor for each of the geometries under study.

Different values for the out-of-straightness of the column ranging from L/500 to L/7500 were studied, producing the results shown in Fig. 12. From this study, it can be recommended that values no higher than L/500 be adopted, being optimum to employ an amplitude of L/1000-L/2000, as normally assumed by researchers. The L/7500 value suggested by Galambos [11] for CFT columns produced good results for some of the specimens studied, but in some cases gave place to convergence problems not being able to induce the overall buckling of the column. 


\subsection{Material mechanical models at elevated temperatures}

Several mechanical models at high temperatures were studied for both steel and concrete.

\section{Steel}

For steel, four models were studied and contrasted: EN 1993-1-2 [7], Lie [19], Yin [26] and Poh [20]. The first one produced the optimal results, whereas the model from Lie predicted an excessively resistant behaviour, as it can be seen in Fig. 13. The models from Yin and Poh did not produce a converged solution, which was attributed to the elasticperfectly plastic shape of the stress-strain curves. The steel model determines the shape and extension of stages 1 and 2 at the axial displacement versus time curve (Fig. 4).

\section{Concrete}

In the case of concrete, a wider variety of mechanical models at elevated temperatures exists in the literature. Five of them were studied in this research: Lie [19], EN 1992-1-2 [6], Anderberg [2], Li-Purkiss [17] and Schneider [24]. The concrete model determines the extension of stage 3 at the axial displacement versus time curve (Fig. 4) and fixes the position of the failure branch (stage 4 at Fig. 4). Among all these models, the model from Lie was the one that best predicted the fire resistance of the columns, as it can be seen in Fig. 14. This model was specifically developed by the author for concrete employed as filling in CFT columns. Regarding EC2, this model produced the most conservative results.

\subsection{Thermal expansion coefficient}

\section{Steel}

Two options were studied for modelling the thermal expansion of steel at elevated temperatures. On one hand, the temperature dependent values of the thermal expansion coefficient from EN 1993-1-2 [7] were studied. On the other hand, the constant value 
recommended by Hong-Varma [14], $\alpha_{s}=12 \times 10^{-6}{ }^{\circ} \mathrm{C}^{-1}$, was checked. The EC3 thermal expansion model produced very accurate results, whereas the constant value proposed by Hong-Varma predicted a shorter maximum axial displacement, as shown in Fig. 15.

\section{Concrete}

Two options were studied for modelling the thermal expansion of concrete at elevated temperatures: the temperature dependent formulation from EN 1992-1-2 [6] and the constant value recommended by Hong-Varma [14], $\alpha_{c}=6 \times 10^{-6}{ }^{\circ} \mathrm{C}^{-1}$. This constant value produced remarkably better results for concrete, as shown in Fig. 16, while the EC2 model resulted in a very unreal response, giving place to excessive axial displacement in the stage when the concrete is sustaining the majority of the applied load (stage 3 at Fig. 4).

\subsection{Concrete moisture}

The moisture content at the concrete infill was modelled through a peak value in the specific heat formulation, as recommended by EN 1994-1-2 [8]. A first peak value of 2020 $\mathrm{J} / \mathrm{kgK}$ corresponding to a moisture content of $3 \%$ in concrete weight was implemented, and a second value of $5600 \mathrm{~J} / \mathrm{kgK}$ for a moisture content of $10 \%$ was next studied. For the siliceous concrete filled specimens, the optimal results were obtained both in thermal and mechanical response with a 3\% moisture value. This is shown in Fig. 17 for the temperature field of column C-02 and in Fig. 18 for the axial displacement response of columns C-04 and C-05. Nevertheless, for those specimens filled with calcareous concrete, the optimal moisture value was found to be a $10 \%$. The real moisture content value at test date, which may be different for each column specimen, was not reported in the literature and therefore a global value suitable for the majority of the tests was adopted in this research. 


\subsection{Concrete density}

The variation of concrete density with temperature formulated in EN 1992-1-2 [6] was studied in contrast to the constant value of $2300 \mathrm{~kg} / \mathrm{m}^{3}$ adopted by most researchers. This study proved that there is no significant influence of this aspect over the fire behaviour of CFT columns, and therefore the figure is not presented here for simplicity to the reader. Thus, the temperature dependence of concrete density can be omitted in the model.

\subsection{Rebar finite element type}

Two different finite element types for modelling the reinforcing steel bars were studied in this research: the two-node truss elements and the three-dimensional solid elements. The truss elements gave a more accurate prediction for the reinforced specimens studied, as it can be seen in Fig. 19, producing an overall more realistic response. Full bond was assumed between the steel reinforcing bars and concrete, tying both rebar nodes to their corresponding concrete nodes.

\subsection{Recommendations}

Based on the results of the sensitivity analysis carried out in this research, several recommendations can be done for the future numerical modelling of CFT columns under fire.

- For modelling the tangent behaviour at the steel-concrete interface, a full slip can be assumed and thus a frictionless contact model adopted, since in fire situation the different thermal expansions cause the transverse separation of the steel tube from the concrete core.

- In case that a Coulomb friction model is selected, the value of the friction coefficient at the steel-concrete interface does not have any influence on the column behaviour under fire. 
- Regarding the gap thermal conductance at the steel-concrete interface, the model proposed by Ghojel [12] produces the best estimations in failure time, although adopting a constant value of $h_{j}=200 \mathrm{~W} / \mathrm{m}^{2} \mathrm{~K}$ is more simplistic and produces acceptable results as well.

- It is recommended to employ an amplitude value of L/1000-L/2000 for the initial geometric imperfection of the columns.

- For steel the EC3 [7] mechanical model produces the most accurate response, while for concrete the model developed by Lie [19] is the one that best predicts the overall behaviour in fire situation.

- The EC3 [7] thermal expansion model gives very accurate results for steel, whereas for concrete the constant value $\alpha_{c}=6 \times 10^{-6}{ }^{\circ} \mathrm{C}^{-1}$ recommended by Hong-Varma [14] produces the best results.

- The optimal results are obtained both in thermal and mechanical response with a moisture content value at the concrete core of $3 \%$ for the siliceous concrete specimens and with a $10 \%$ for the calcareous ones, even though this variable should be reported in the tests for every specimen and its exact value introduced to the model.

- A constant value of $2300 \mathrm{~kg} / \mathrm{m}^{3}$ is sufficient for modelling the concrete density. There is no significant influence of the temperature variation of this parameter over the fire behaviour of the columns.

- It is recommended to employ the two-node truss finite elements for modelling the longitudinal steel bars in the reinforced column specimens. 


\section{COMPARISON WITH EUROCODE 4 SIMPLE CALCULATION MODEL}

In this section, the validated numerical model will be used to study and discuss the EC4 simple calculation model [8]. This standard provides a simple method for calculating the fire resistance of CFT columns subjected to concentric axial loads. For eccentrically loaded columns, an equivalent concentric load is obtained by means of two factors, which are a function of the percentage of reinforcement and the relative eccentricity.

Only those columns with concrete filling resistance under $40 \mathrm{MPa}$ will be used for this study, as the current field of application of EC4 is C20/25-C40/50.

As already found by Aribert et al. [3], the EC4 simple calculation model does not take into account the effects of self-equilibrated thermal stresses and those of geometrical secondorder local behaviour, which are crucial for the stability of the column. As the method is sectional, the strain in all the fibres within the cross-section of the column is assumed to be equal. This approach clearly neglects the effects of the differential longitudinal expansion between the steel tube and concrete core, thus assuming that a full bond occurs. All these factors lead to important deviations from the actual fire response of CFT columns.

\subsection{Concentric axial load}

\section{a) Influence of the thermal expansion}

One of the most important factors affecting the accuracy of EC4 simple calculation model is the differential longitudinal thermal expansion between the steel tube and the concrete core, which can not be taken into account through a sectional approach as the one in EC4. If the same assumptions adopted by EC4 are applied to the numerical model (no thermal expansion occurs, no thermal resistance exists at the steel-concrete interface, all the column is uniformly exposed to a standard fire), more similar results to those predicted by EC4 are obtained, as it can be seen in Table 5 and Fig. 20. These results seem to confirm that EC4 
neglects the differential thermal expansion effect. With these assumptions applied to the numerical model, a more conservative trend but still parallel to the real trend is obtained, which could be used to improve the accuracy and extension of the EC4 provisions.

\section{b) Influence of the temperature field}

It is known that the EC4 simple calculation model for obtaining the fire resistance of unprotected concrete filled hollow section columns in axial compression requires the crosssectional temperature field to be previously known and applied as a first step. Therefore, the calculated axial buckling load in fire will be influenced by the level of accuracy of the thermal distribution employed by the designer. This influence is studied hereafter.

\section{b.1) Fixed-fixed end conditions}

On a first level of comparison, the fixed-fixed specimens from the Canadian tests were contrasted with the predictions of the EC4 simple calculation model, employing both an ideal temperature field calculated assuming perfect thermal contact and the real temperature field obtained by means of the validated numerical model. The results are listed in Table 6 and plotted in Fig. 21. It was found that when the real temperature distribution over the crosssection was adopted, the EC4 simple calculation model produced unsafe results for those columns with the highest relative slenderness.

Special mention must be done regarding this aspect. EC4 establishes that the thermal resistance between the steel wall and the concrete core may be neglected in the calculation of the cross-sectional temperature field. This is a conservative assumption which leads to safe results, but the structural engineer must be aware that when adopting a more complex temperature field obtained by means of any advanced model the results of EC4 can turn into the unsafe side. The temperature field employed as a previous step for calculating the axial buckling load at elevated temperature with EC4 simple calculation model must be therefore carefully considered, since it can noticeably influence the simple model predictions. 


\section{b.2) Pinned-pinned end conditions}

On a second level of comparison, the same specimens were simulated hinged at both ends, and the results compared with the predictions of the EC4 simple calculation model employing both the ideal temperature field and the real temperature field. The results are listed in Table 7 and plotted in Fig. 22. For most of these cases, the EC4 model became unsafe, since the buckling length of the columns was higher. Only those cases corresponding to the massive columns remained on the safe side. The influence of the adopted temperature field was noticeable again, in such a way that employing a real temperature field moves the trend of the results series towards the unsafe side.

In general, it can be concluded that for centrally loaded columns, values of the relative slenderness at ambient temperature greater than 0.4 lead to unsafe results, as in can be seen in Fig. 23. This fact was already confirmed by Aribert et al. [3], who found that EC4 simple calculation model leads to buckling load values that are quite unsafe when the column slenderness increases.

\subsection{Eccentrically loaded columns}

Finally, the same series of pinned-pinned columns were simulated introducing a $20 \mathrm{~mm}$ and $50 \mathrm{~mm}$ eccentricity and afterwards compared with the EC4 simple calculation model predictions employing both the ideal temperature field and the real temperature field. The results are listed in Table 8 and plotted in Fig. 24 for the $20 \mathrm{~mm}$ eccentric specimens. In these cases, the simple calculation model produced results that were on the safe side, due to the application of the corresponding reduction factors. Thus, for eccentrically loaded columns, it can be concluded that EC4 simple calculation model becomes conservative.

Regarding the temperature field adopted as the previous step for applying the simple calculation model, it showed not to have a significant influence for eccentrically loaded columns. 
Summarizing all the findings exposed above, this extensive study evidences some limitations in the EC4 simple calculation model when predicting the axial buckling load of concrete filled hollow steel sections at elevated temperatures and suggests that the model should be revised in the future on the bases of these findings.

\section{SUMMARY AND CONCLUSIONS}

A realistic three-dimensional numerical model for predicting the fire response of axially loaded CFT columns was presented. By means of this model, the fire behaviour of a series of column specimens previously tested by other researchers was predicted. The numerical model showed good agreement with the tests both quantitative, producing acceptable results in fire resistance rating, and qualitative, capturing the overall axial displacement response along time. There was better agreement for the leaner columns, whereas the massive columns produced more error, which was attributed to the higher contribution of concrete and its more complex failure mechanisms.

The behaviour of CFT columns with concrete fillings in the medium strength range was also explored but could not be so well captured in this initial research work, due to the local effects associated to micro-cracking that appear in non-reinforced HSC at elevated temperatures. Despite this aspect, the model showed good agreement when contrasted with the fire tests of CFT columns in the range of the normal strength, which was the scope of this paper. The aim of future work will be to extend the model to high strength concrete, including the simulation of the effect of spalling.

By means of the validated numerical model, an extensive sensitivity analysis was carried out, covering the main aspects of the problem. With the results of this sensitivity study a number of modelling recommendations for CFT columns in fire were given in this paper.

This research also proved that the EC4 simple calculation model may lead to unsafe results when working with columns with relative slenderness values over 0.4 and in general 
for pinned-pinned columns under concentric axial load. Moreover, it was found that applying a realistic predefined temperature field to the model can magnify this effect. However, EC4 simple calculation model becomes highly conservative for eccentric loads.

The simple calculation model should be therefore improved based on the results of this paper. In future work it will be intended to capture the failure mechanism of high strength concrete filled specimens, in order to create a virtual laboratory for simulating a wider range of cases that can be used to extend and improve the current provisions of EC4.

\section{ACKNOWLEDGEMENTS}

The authors express their sincere gratitude to the Spanish "Ministerio de Ciencia e Innovación" for the help provided through the Project BIA2009-9411 and to the European Union through the FEDER funds.

\section{REFERENCES}

[1] ABAQUS. ABAQUS/Standard Version 6.6 User's Manual: Volumes I-III. Pawtucket, Rhode Island: Hibbit, Karlsson \& Sorenson, Inc.; 2005.

[2] Anderberg Y, Thelandersson S. Stress and deformation characteristics of concrete at high temperatures - Experimental investigation and material behaviour model. Bulletin 54. Lund, Sweden: Lund Institute of Technology; 1976.

[3] Aribert JM, Renaud C, Zhao B. Simple fire design for composite hollow-section columns. Structures \& Buildings 2008; 161:325-336.

[4] ASTM. Standard ASTM E119-88: Standard methods of fire test of building construction and materials. Philadelphia, Pa: American Society for Testing and Materials; 1990.

[5] CEN. EN 1991-1-2, Eurocode 1: Actions on structures, Part 1.2: General actions Actions on structures exposed to fire. Brussels, Belgium: Comité Européen de Normalisation; 2002. 
[6] CEN. EN 1992-1-2, Eurocode 2: Design of concrete structures, Part 1.2: General rules Structural fire design. Brussels, Belgium: Comité Européen de Normalisation; 2004.

[7] CEN. EN 1993-1-2, Eurocode 3: Design of steel structures, Part 1.2: General rules Structural fire design. Brussels, Belgium: Comité Européen de Normalisation; 2005.

[8] CEN. EN 1994-1-2, Eurocode 4: Design of composite steel and concrete structures, Part 1.2: General rules - Structural fire design. Brussels, Belgium: Comité Européen de Normalisation; 2005.

[9] Chabot M, Lie TT. Experimental studies on the fire resistance of hollow steel columns filled with bar-reinforced concrete. Internal report No. 628. Ottawa, Canada: Institute for Research in Construction, National Research Council of Canada (NRCC); 1992.

[10] Ding J, Wang YC. Realistic modelling of thermal and structural behaviour of unprotected concrete filled tubular columns in fire. Journal of Constructional Steel Research 2008; 64:1086-1102.

[11] Galambos TV. Guide to stability design criteria for metal structures. Fifth edition. New York: John Wiley and Sons Inc.; 1998.

[12] Ghojel J. Experimental and analytical technique for estimating interface thermal conductance in composite structural elements under simulated fire conditions. Experimental Thermal and Fluid Science 2004; 28:347-354.

[13] Grandjean G, Grimault JP, Petit L. Determination de la duree au feu des profils creux remplis de beton. CIDECT Research Project 15B-80/10. Cologne, Germany: Comité International pour le Développement et l'Etude de la Construction Tubulaire; 1980.

[14] Hong S, Varma AH. Analytical modeling of the standard fire behavior of loaded CFT columns. Journal of Constructional Steel Research 2009; 65:54-69. 
[15] ISO (International Standards Organization). ISO 834: Fire resistance tests, elements of building construction. Switzerland: International Standards Organisation; 1980.

[16] Kordina K, Klingsch W. Fire resistance of composite columns of concrete filled hollow sections. CIDECT Research Project 15C1/C2-83/27. Cologne, Germany: Comité International pour le Développement et l'Etude de la Construction Tubulaire; 1983.

[17] Li LY, Purkiss J. Stress-strain constitutive equations of concrete material at elevated temperatures. Fire Safety Journal 2005; 40(7):669-686.

[18] Lie TT, Chabot M. Experimental studies on the fire resistance of hollow steel columns filled with plain concrete. Internal report No. 611. Ottawa, Canada: Institute for Research in Construction, National Research Council of Canada (NRCC); 1992.

[19] Lie TT. Fire resistance of circular steel columns filled with bar-reinforced concrete. Journal of Structural Engineering-ASCE 1994; 120(5):1489-1509.

[20] Poh KW. Stress-strain-temperature relationships for structural steel. Journal of Materials in Civil Engineering 2001; 13(5):371-379.

[21] Renaud C, Aribert JM, Zhao B. Advanced numerical model for the fire behaviour of composite columns with hollow steel section. Steel and Composite Structures 2003; $3(2): 75-95$.

[22] Renaud C, Joyeux D, Kruppa J. Improvement and extension of the simple calculation method for fire resistance of unprotected concrete filled hollow columns. CIDECT Research Project 15Q-12/03. Saint-Rémy-lès-Chevreuse Cedex, France: Centre Technique Industriel de la Construction Métallique (CTICM); 2004.

[23] Schaumann P, Kodur V, Bahr O. Fire behaviour of hollow structural section steel columns filled with high strength concrete. Journal of Constructional Steel Research $2009 ; 65: 1794-1802$. 
[24] Schneider U, Haksever A. Bestimmung der aquialenten branddauer vor statisch bestimmt gelagerten stahlbetonbalken bei naturlichen branden. Bericht des Instituts fur Baustoffkunde und Stahlbetonbau der Technischen Universität Braunschweig; 1976.

[25] Twilt L, Hass R, Klingsch W, Edwards M, Dutta D. Design guide for structural hollow section columns exposed to fire. Cologne, Germany: Comité International pour le Développement et l'Etude de la Construction Tubulaire (CIDECT); 1996.

[26] Yin J, Zha XX, Li LY. Fire resistance of axially loaded concrete filled steel tube columns. Journal of Constructional Steel Research 2006; 62(7):723-729.

[27] Zha XX. FE analysis of fire resistance of concrete filled CHS columns. Journal of Constructional Steel Research 2003; 59:769-779. 


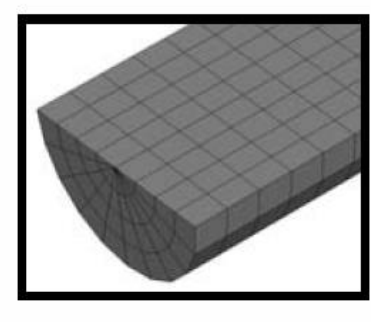

CONCRETE CORE

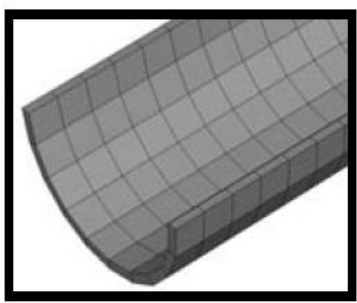

STEEL TUBE

Fig. 1. Three-dimensional finite element model for CFT columns. 
Espinos A, Romero ML, Hospitaler A. Advanced model for predicting the fire response of concrete filled tubular columns. J
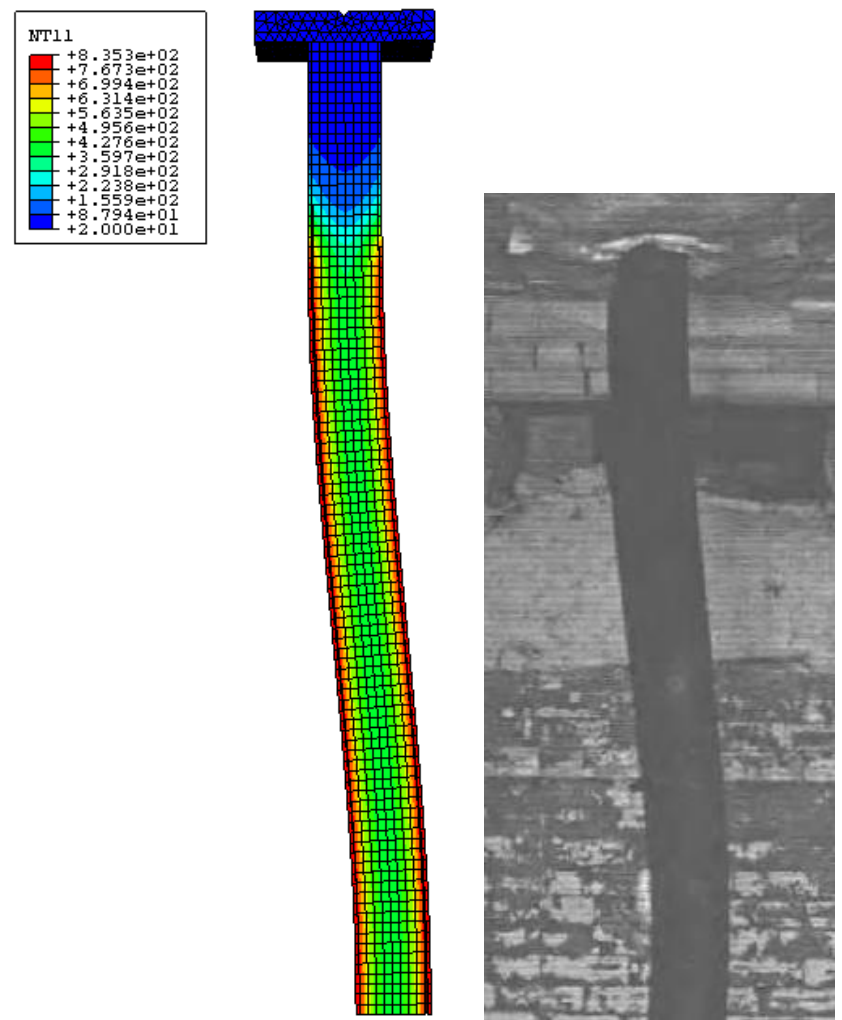

Fig. 2. Deformed shape after exposure to standard fire, for column C-04 [18]. 


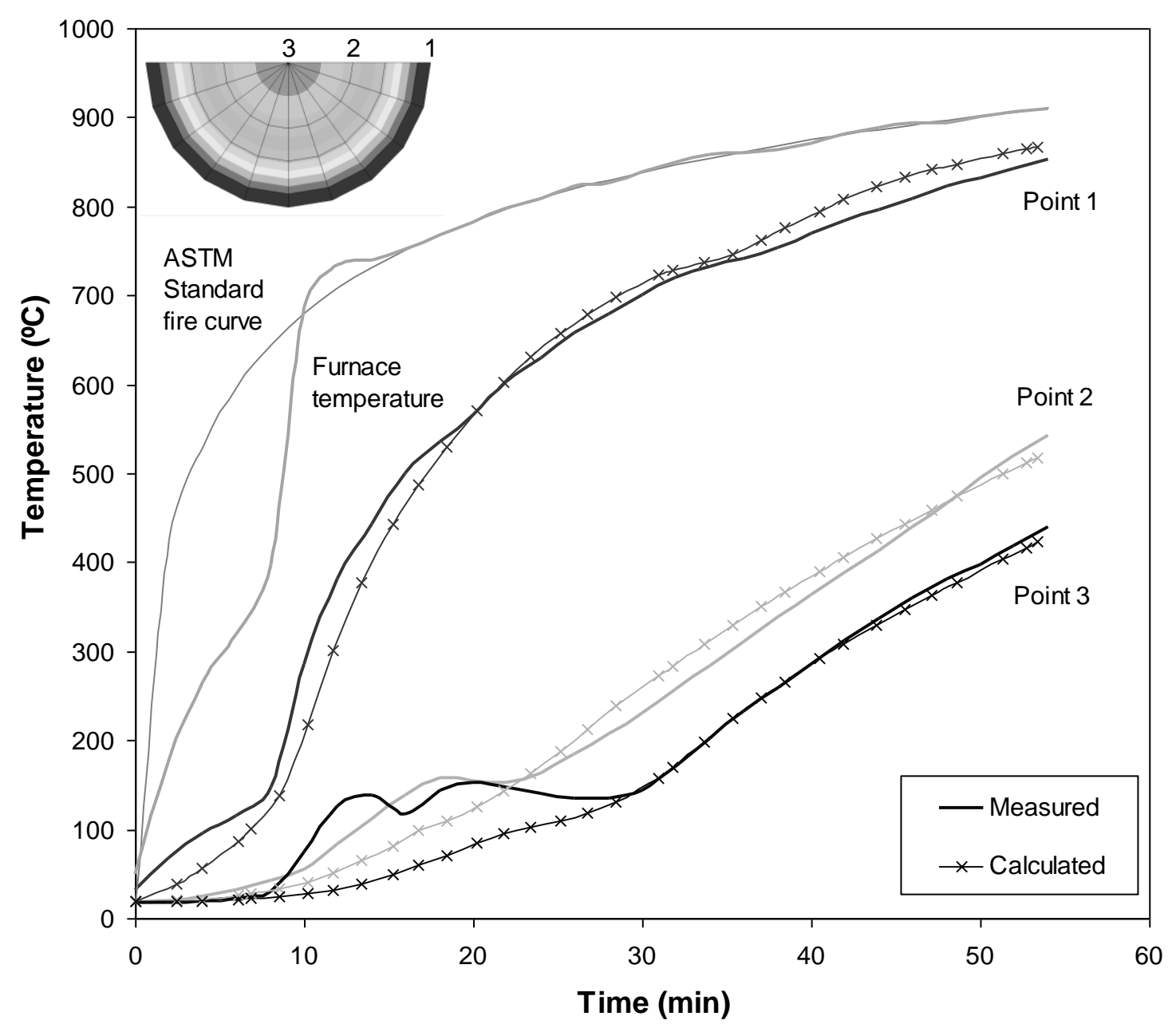

Fig. 3. Comparison between measured and predicted temperatures for column C-02. 


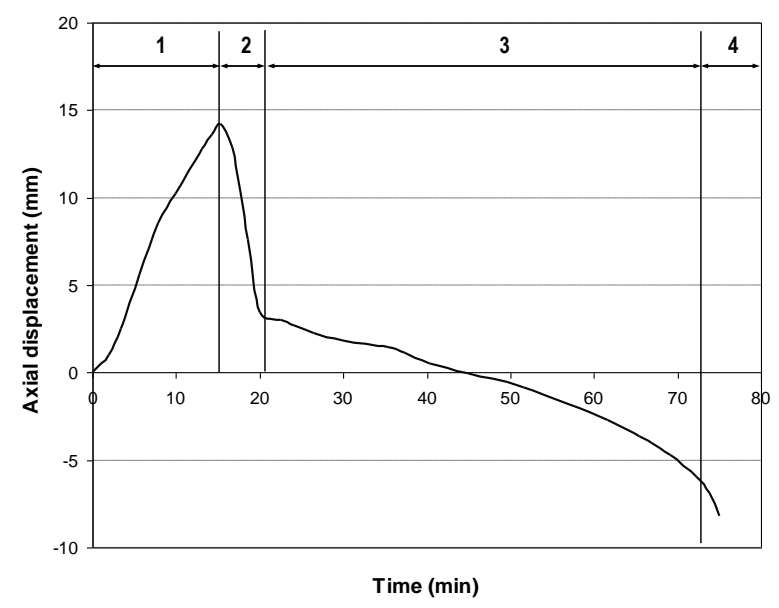

(a) Axial displacement versus time

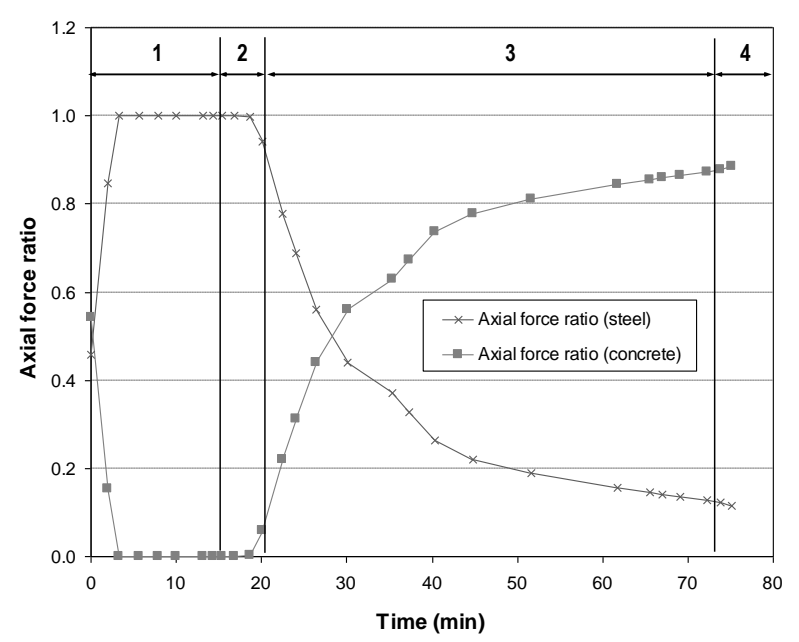

(b) Axial force ratio versus time

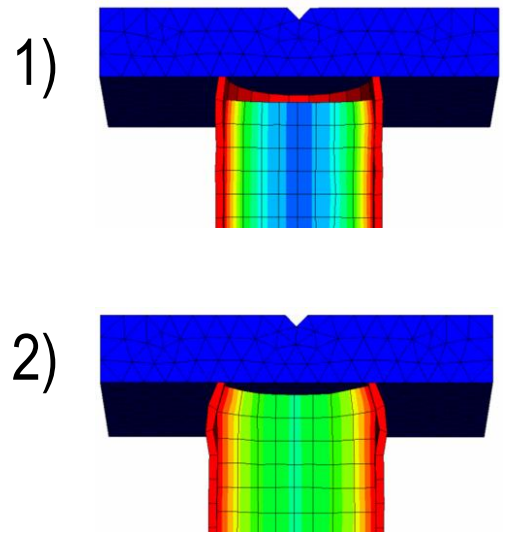

3)

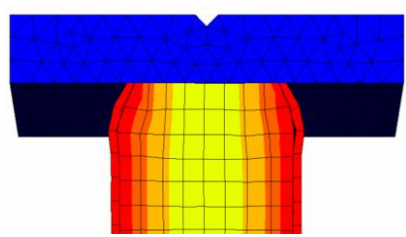

4)

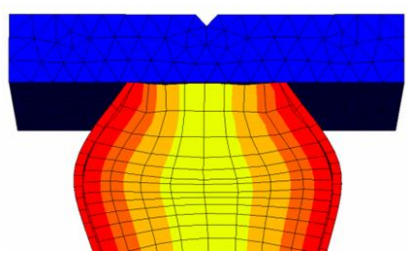

(c) Stages of the fire response of a CFT column

Fig. 4. Axial displacement and axial force ratio versus time, for column C-11. 


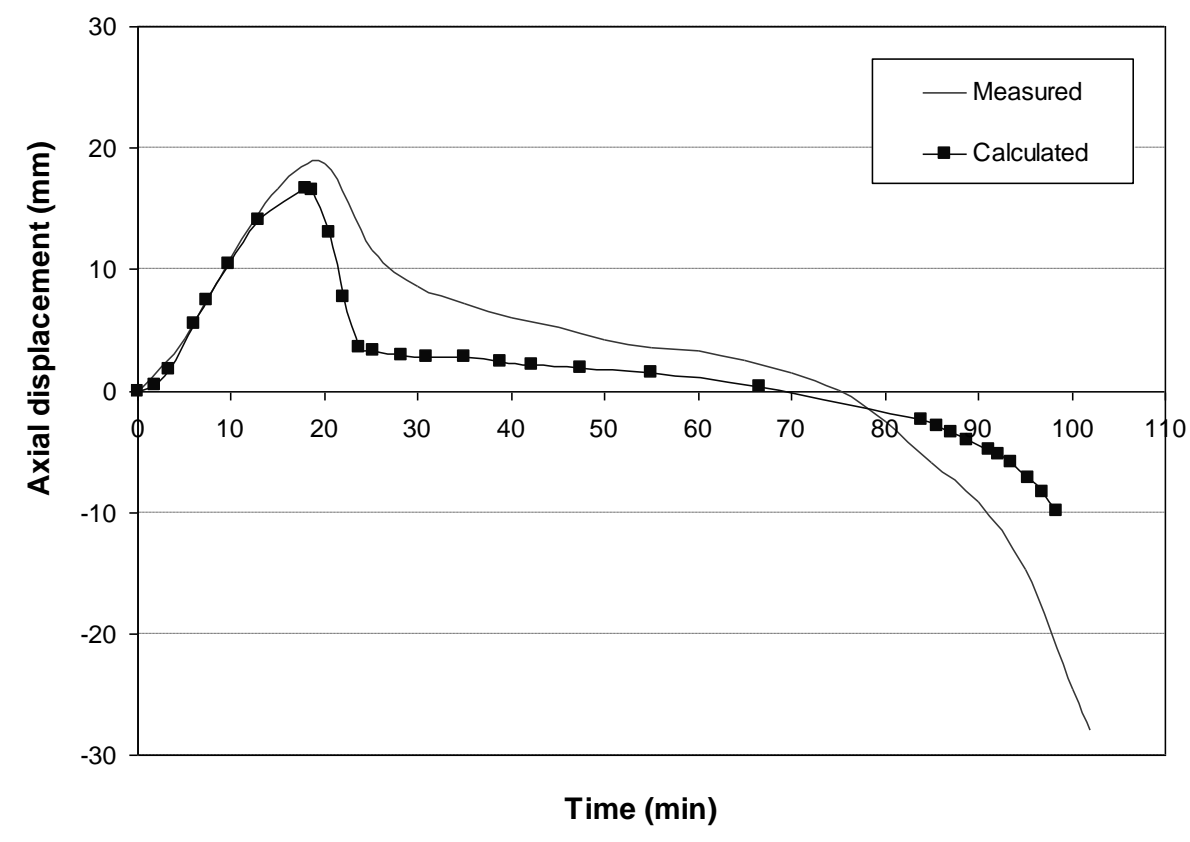

(a) Column C-13

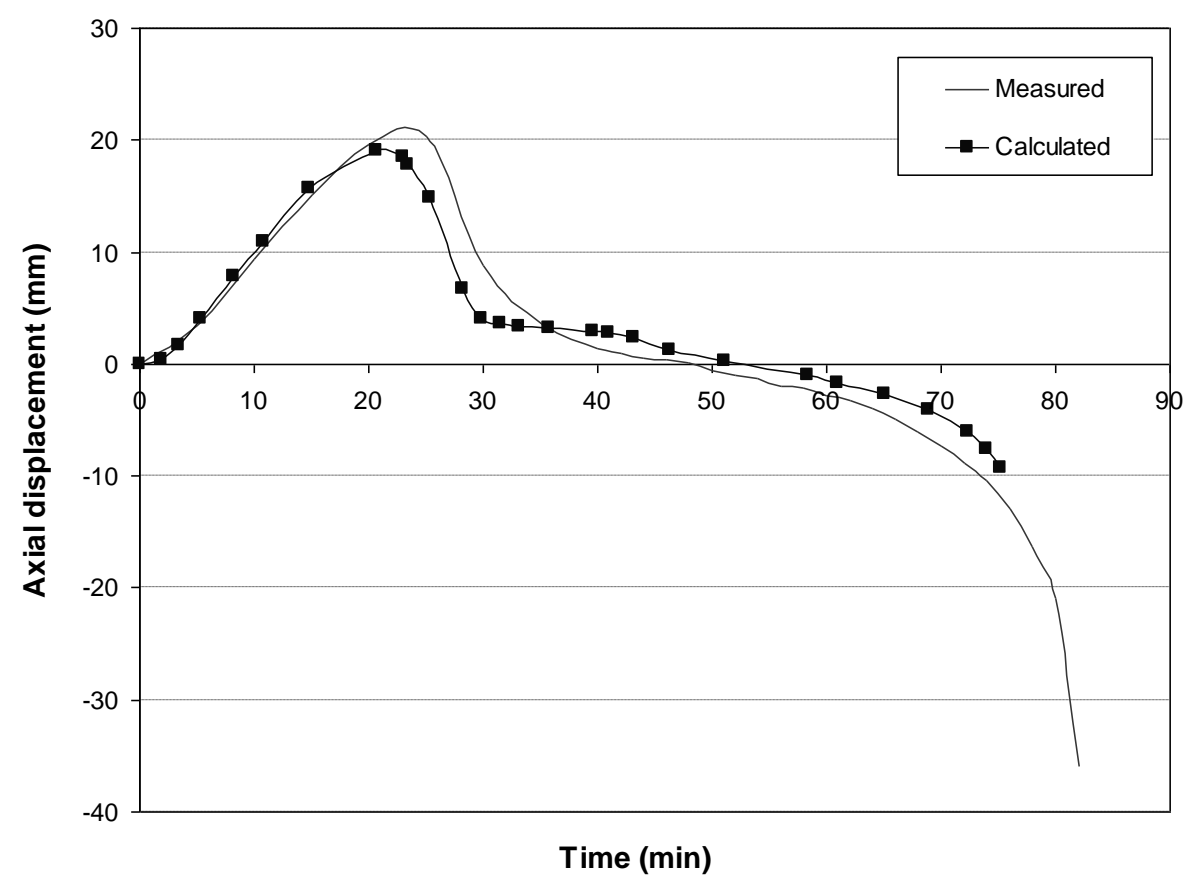

(b) Column C-17

Fig. 5. Comparison of measured and predicted axial displacement. 


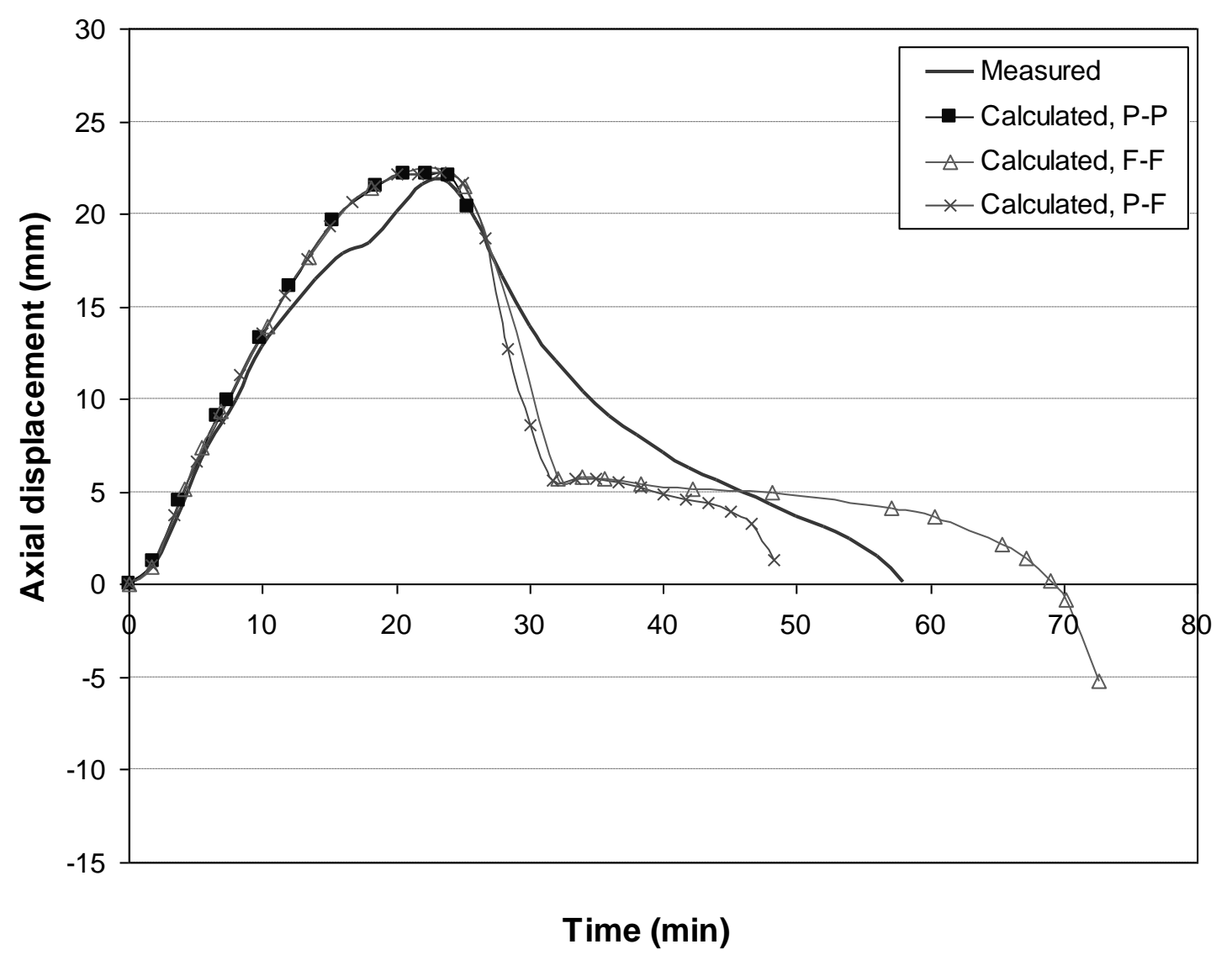

Fig. 6. Comparison of measured and predicted axial displacement with different supporting conditions, for column C-06. 


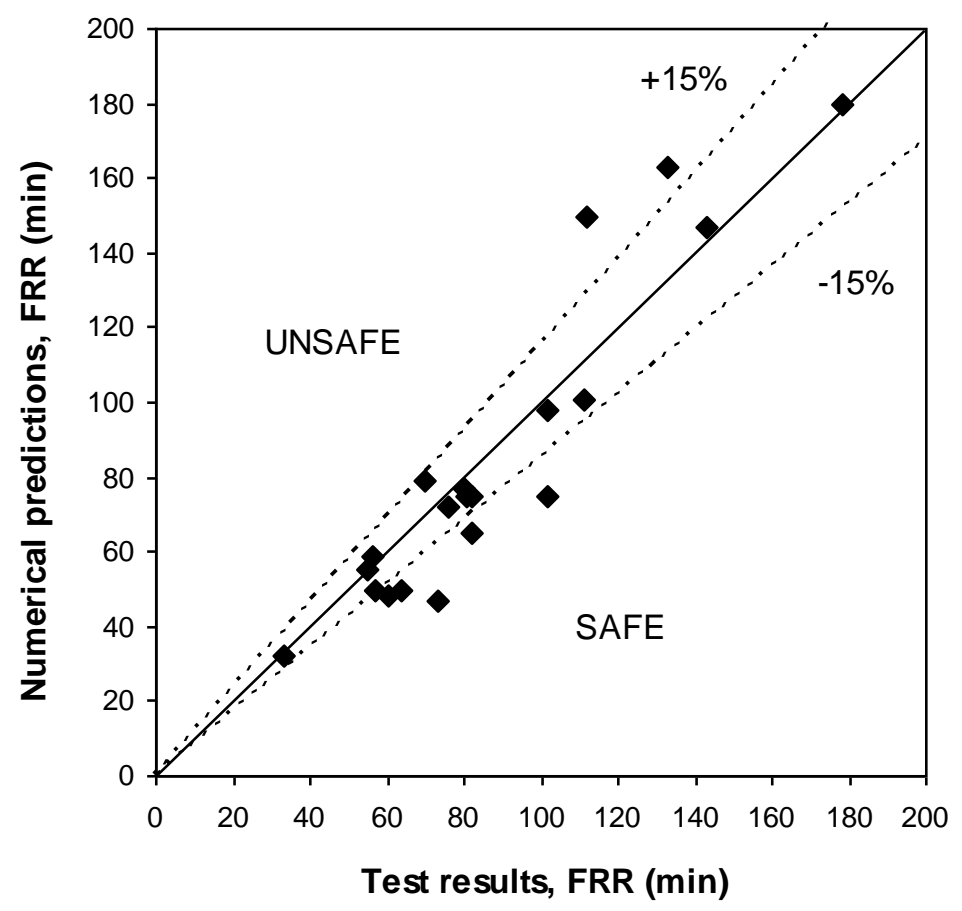

Fig. 7. Comparison of fire resistance rating between calculated and test results, $f_{c}<40 \mathrm{MPa}$. 


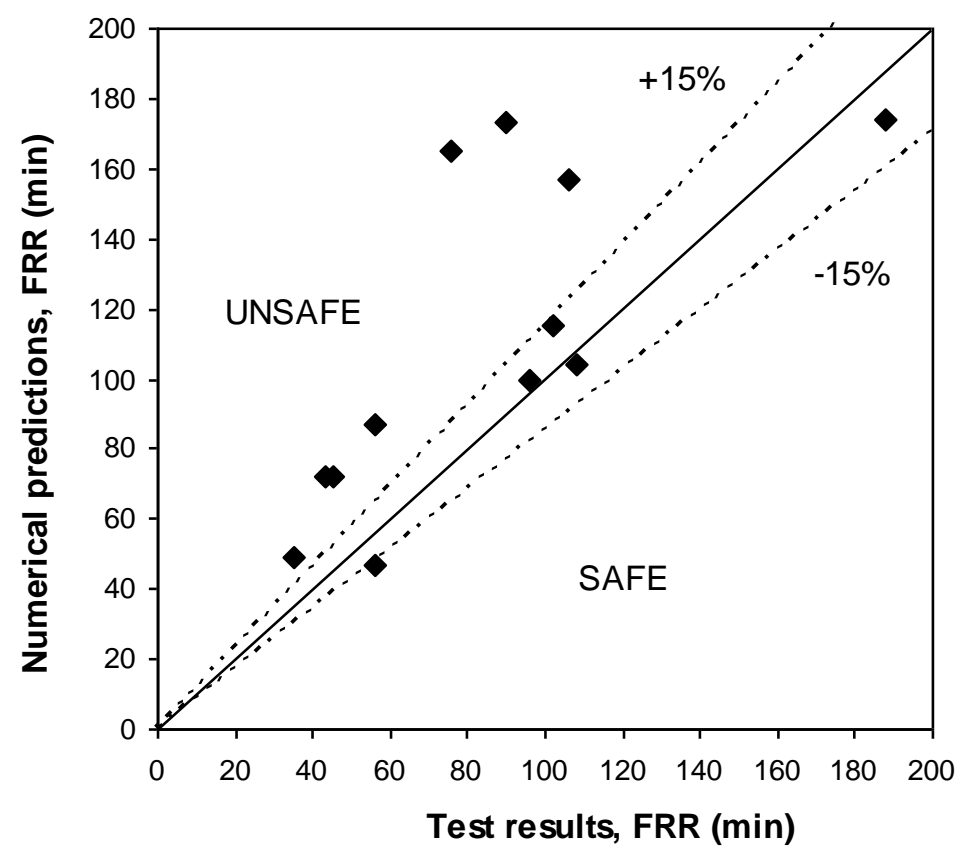

Fig. 8. Comparison of fire resistance rating between calculated and test results, $f_{c}>40 \mathrm{MPa}$. 


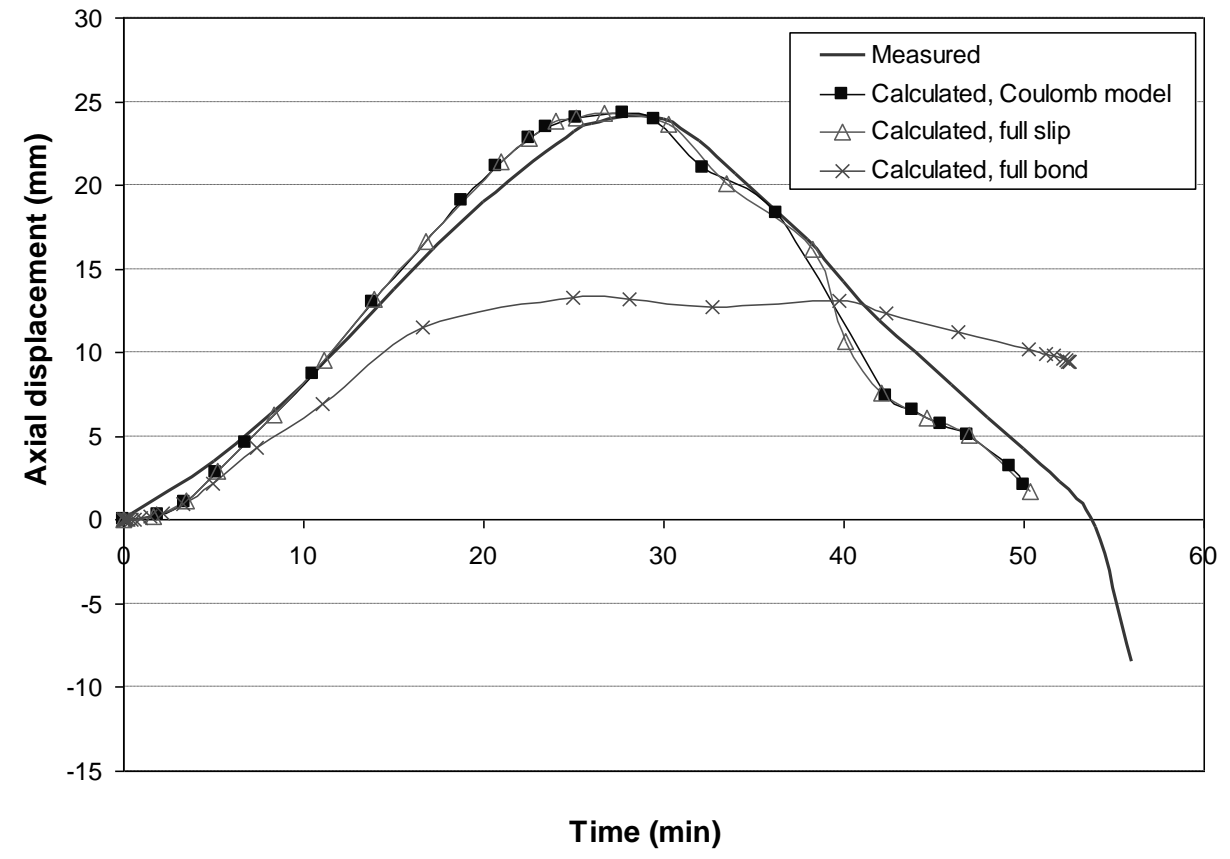

(a) Column C-04

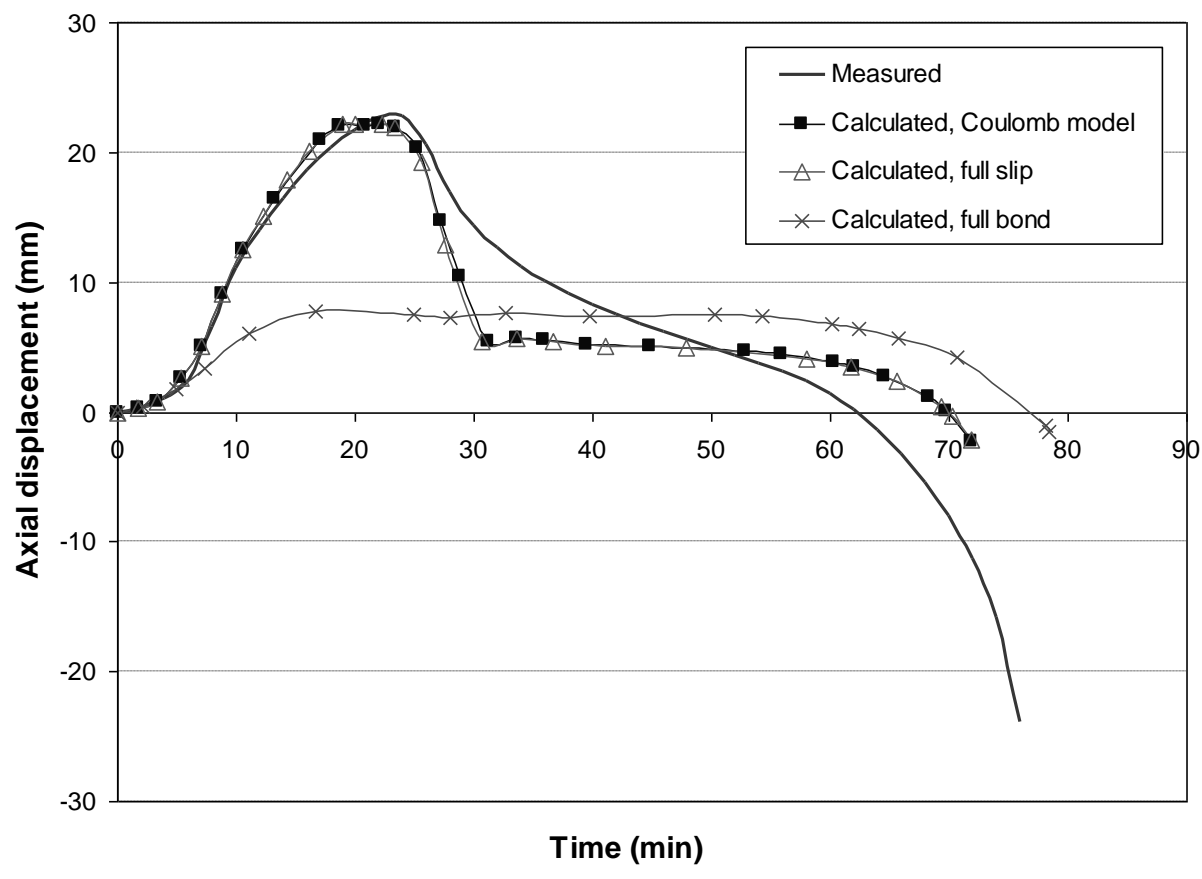

(b) Column C-05

Fig. 9. Comparison of measured and predicted axial displacement with different friction models. 


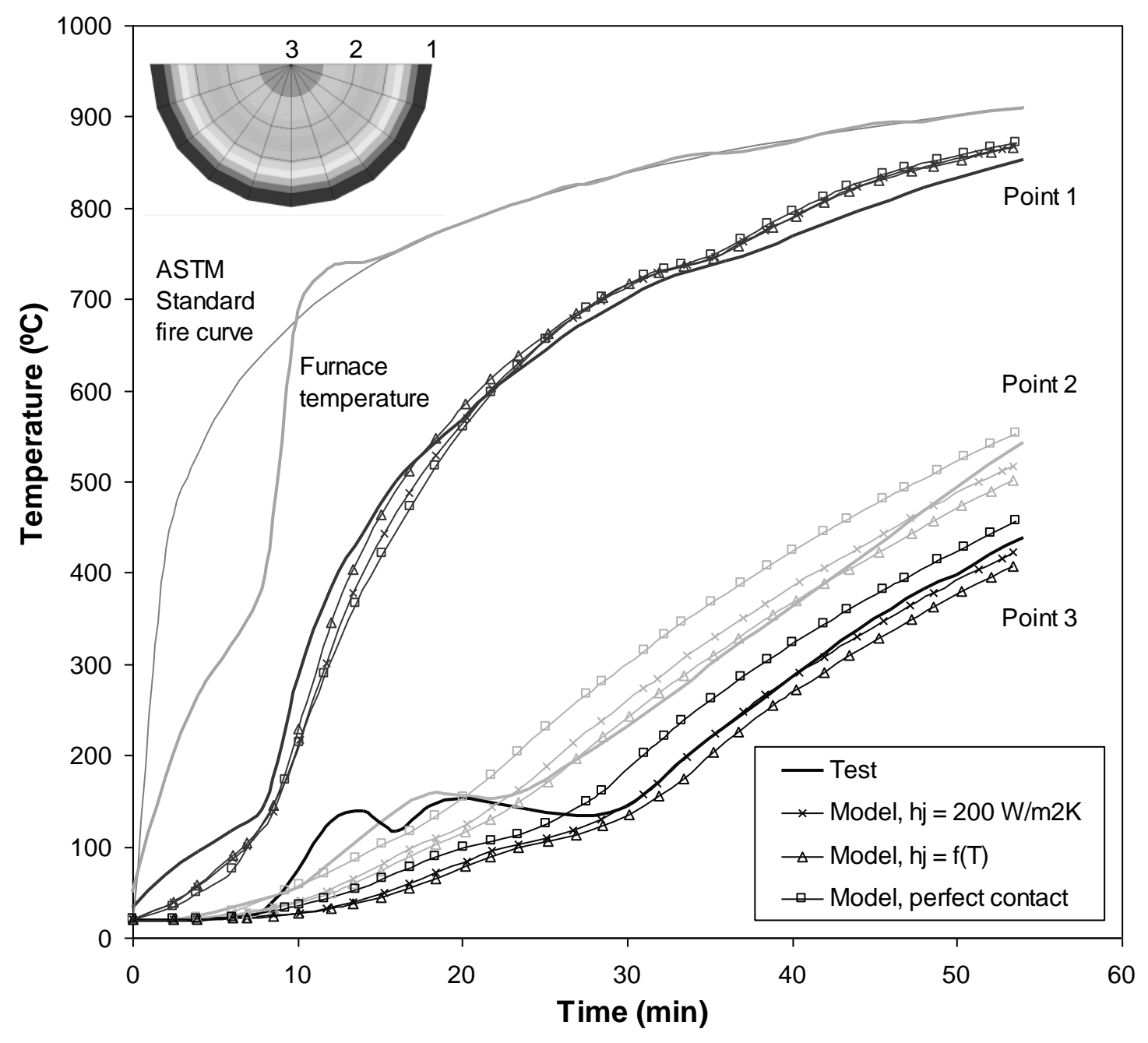

Fig. 10. Comparison between measured and predicted temperatures with different gap conductance values, for column C-02. 


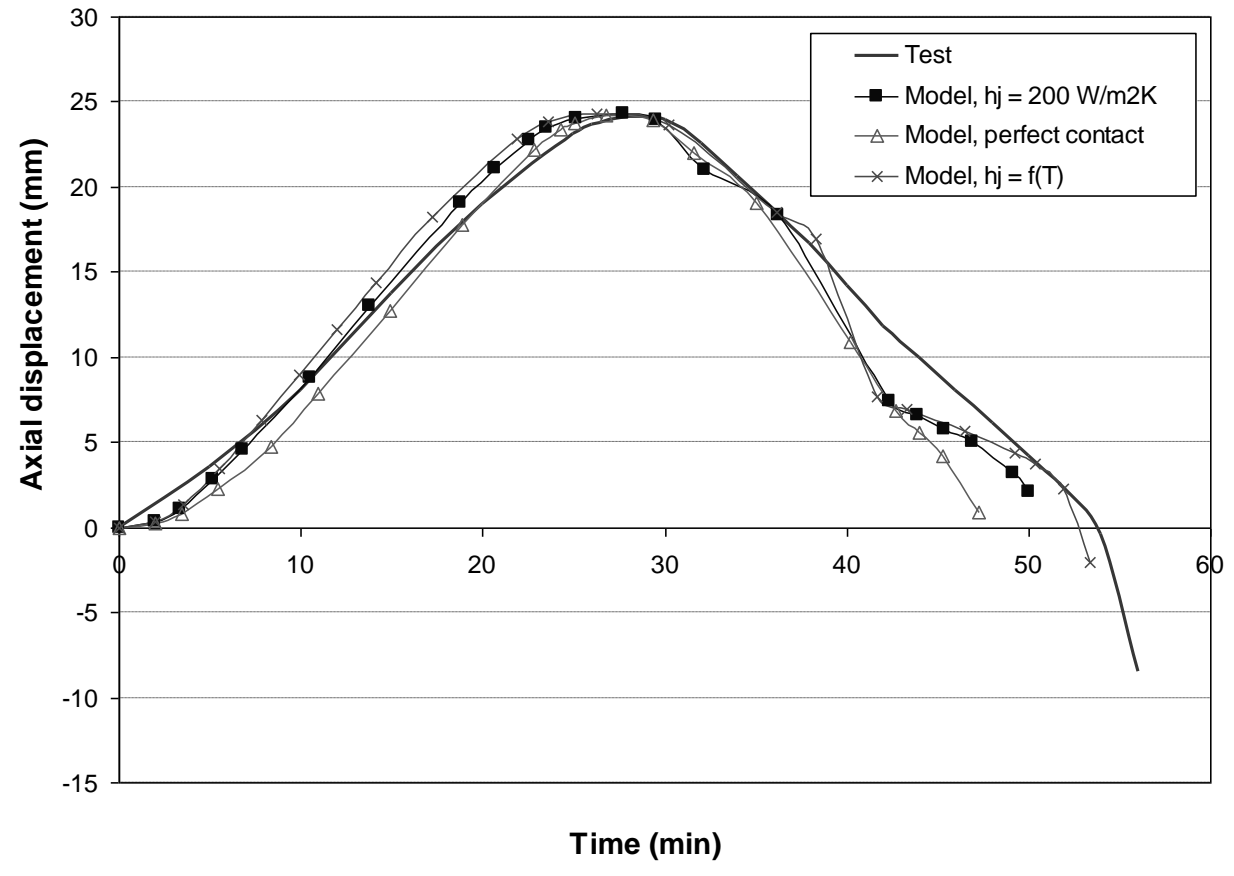

(a) Column C-04

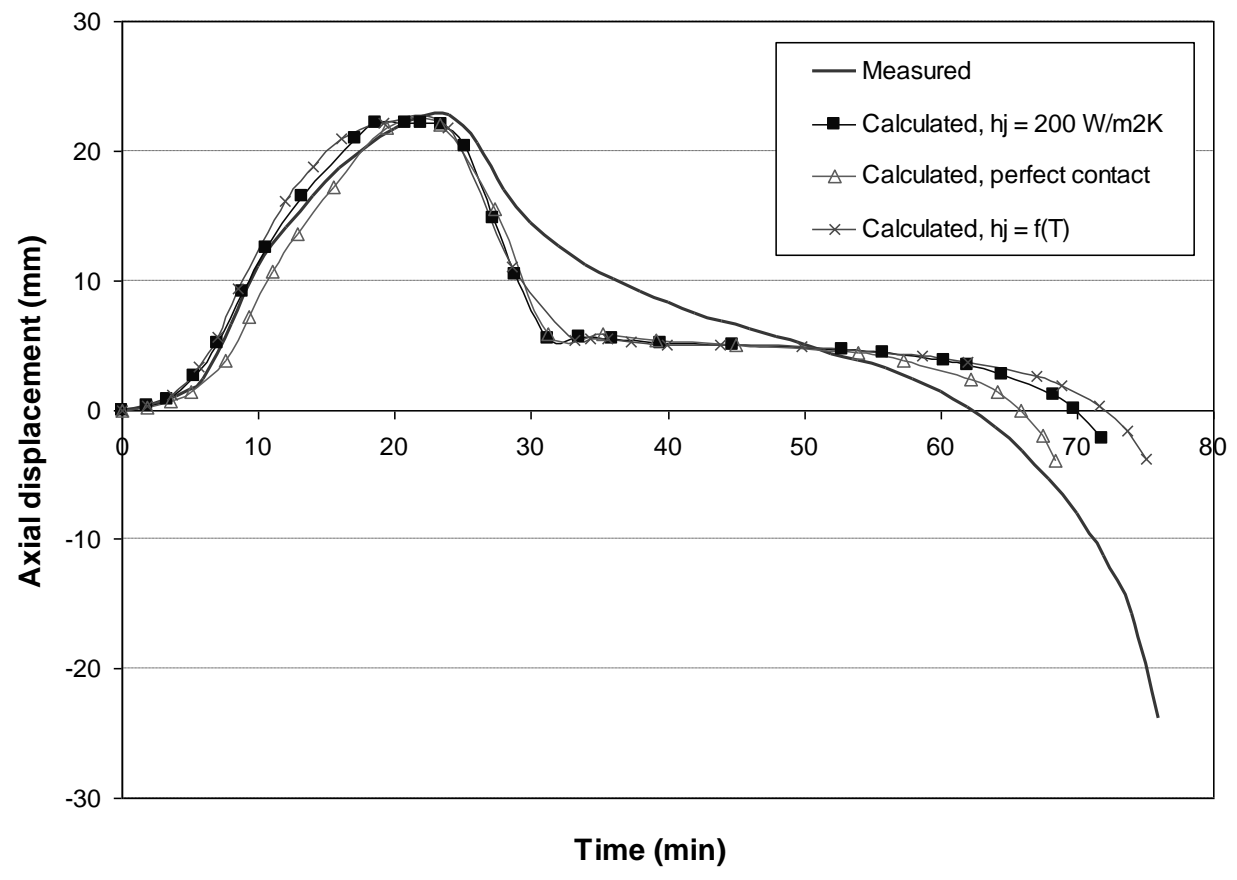

(b) Column C-05

Fig. 11. Comparison of measured and predicted axial displacement with different gap conductance values. 


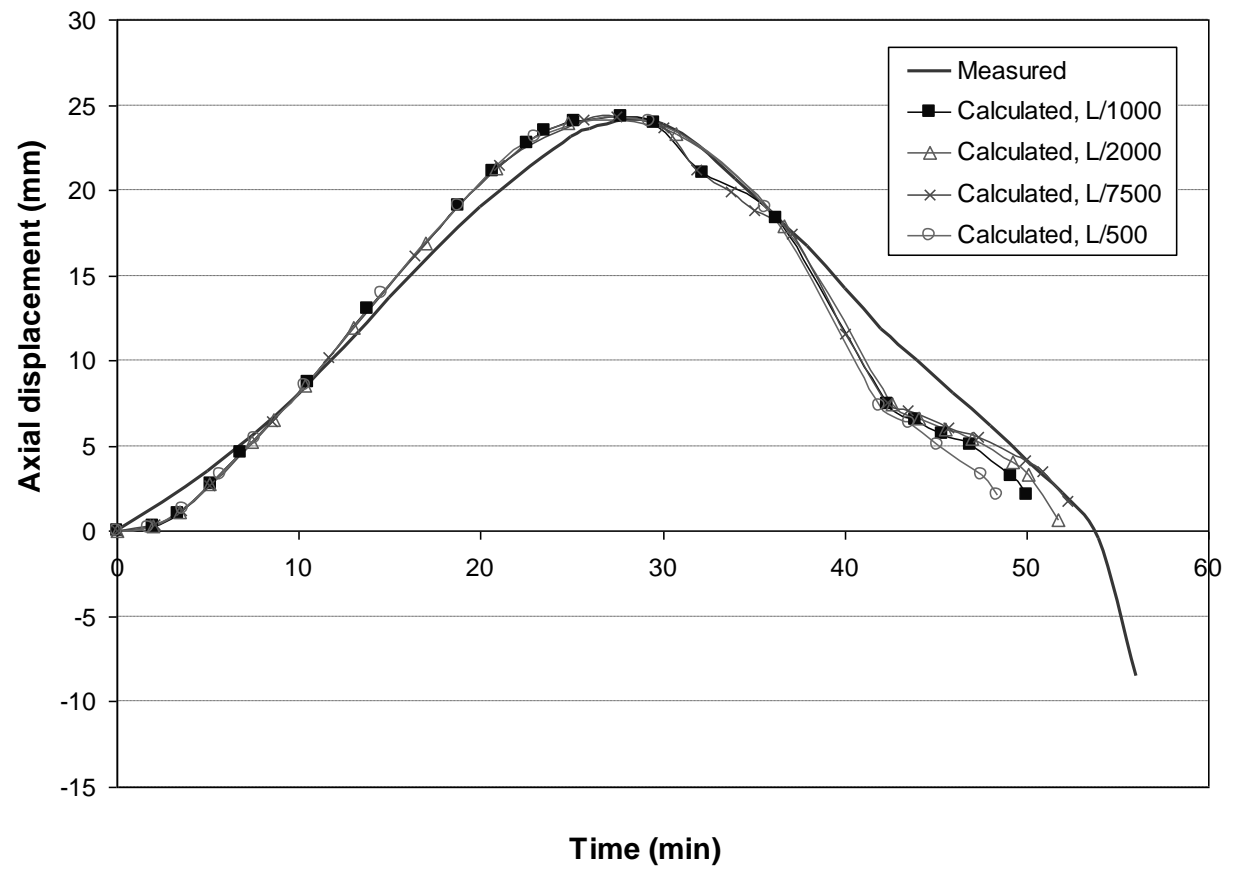

(a) Column C-04

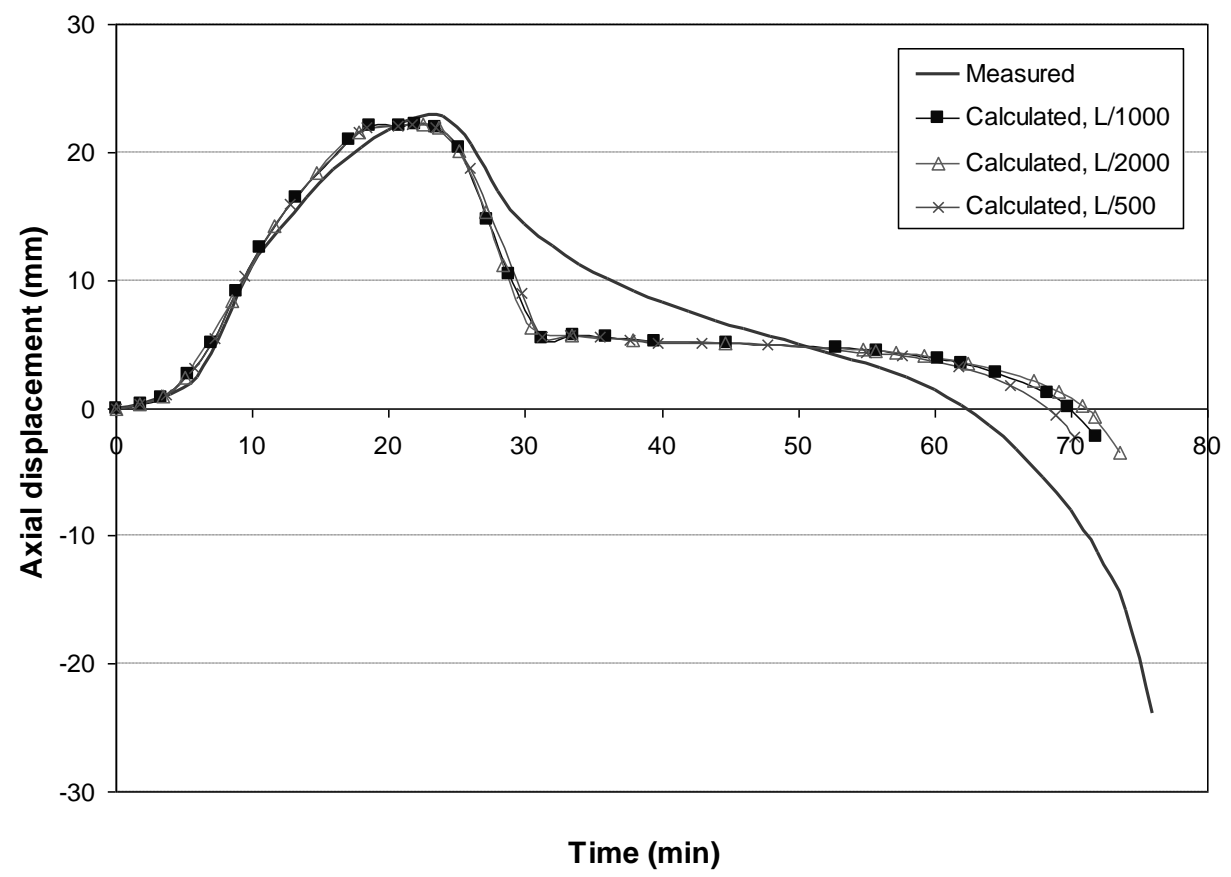

(b) Column C-05

Fig. 12. Comparison of measured and predicted axial displacement with different initial imperfections. 


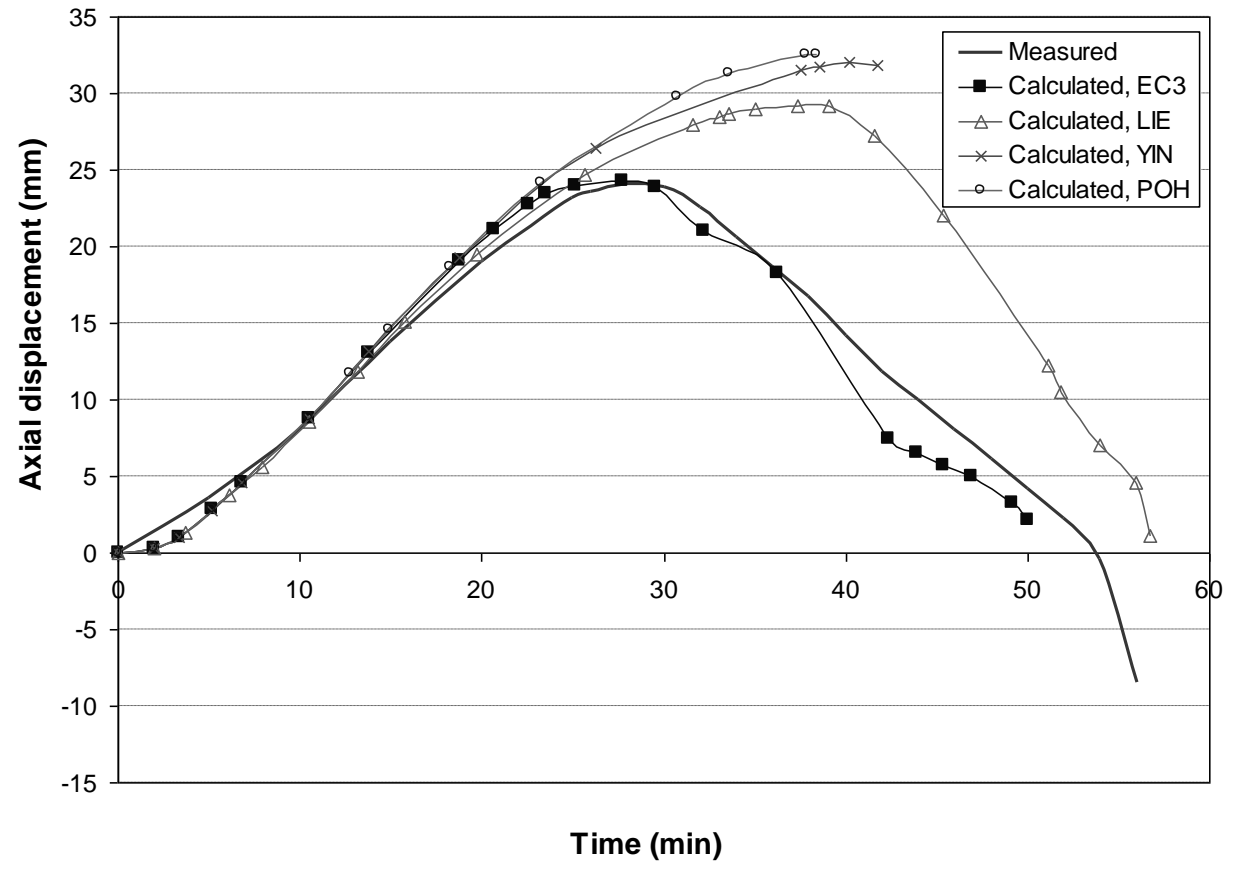

(a) Column C-04

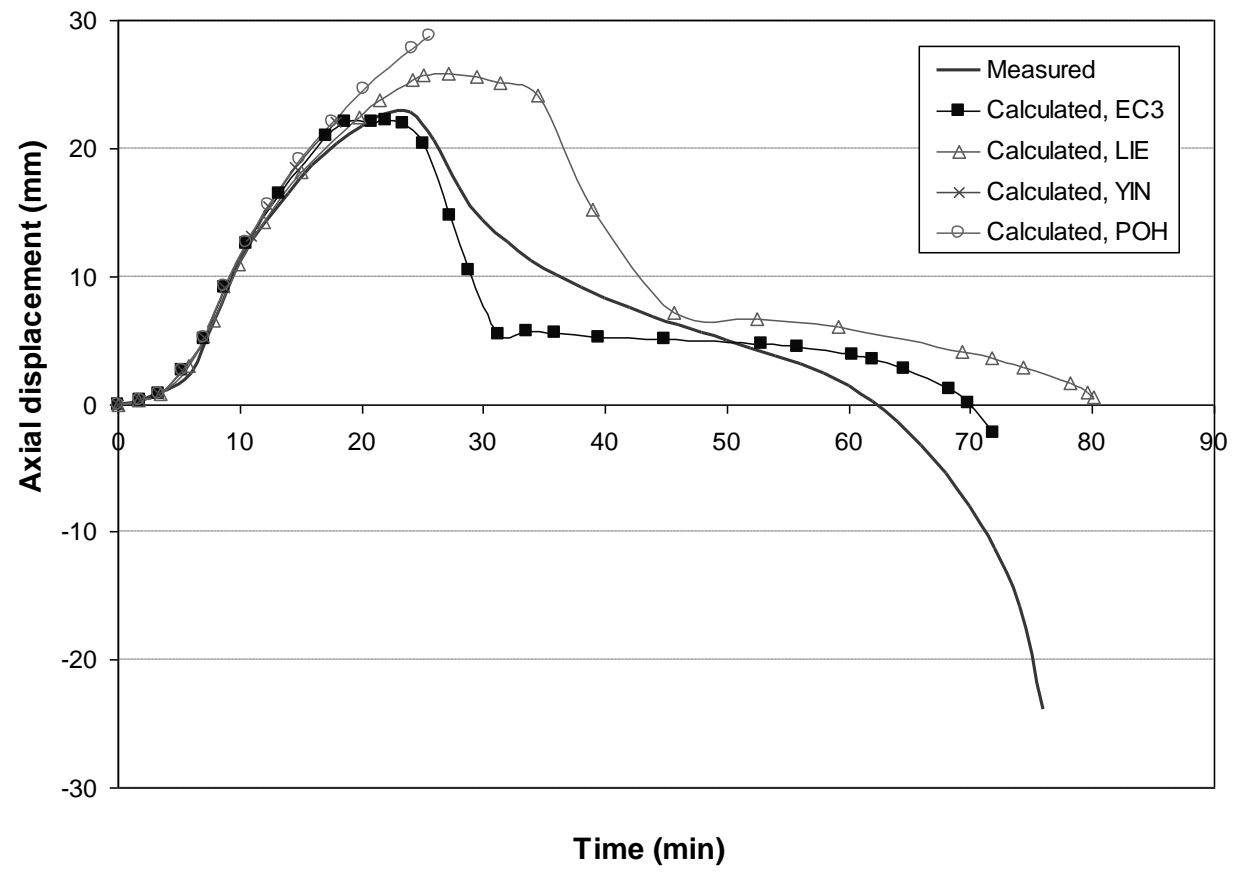

(b) Column C-05

Fig. 13. Comparison of measured and predicted axial displacement with different steel models. 


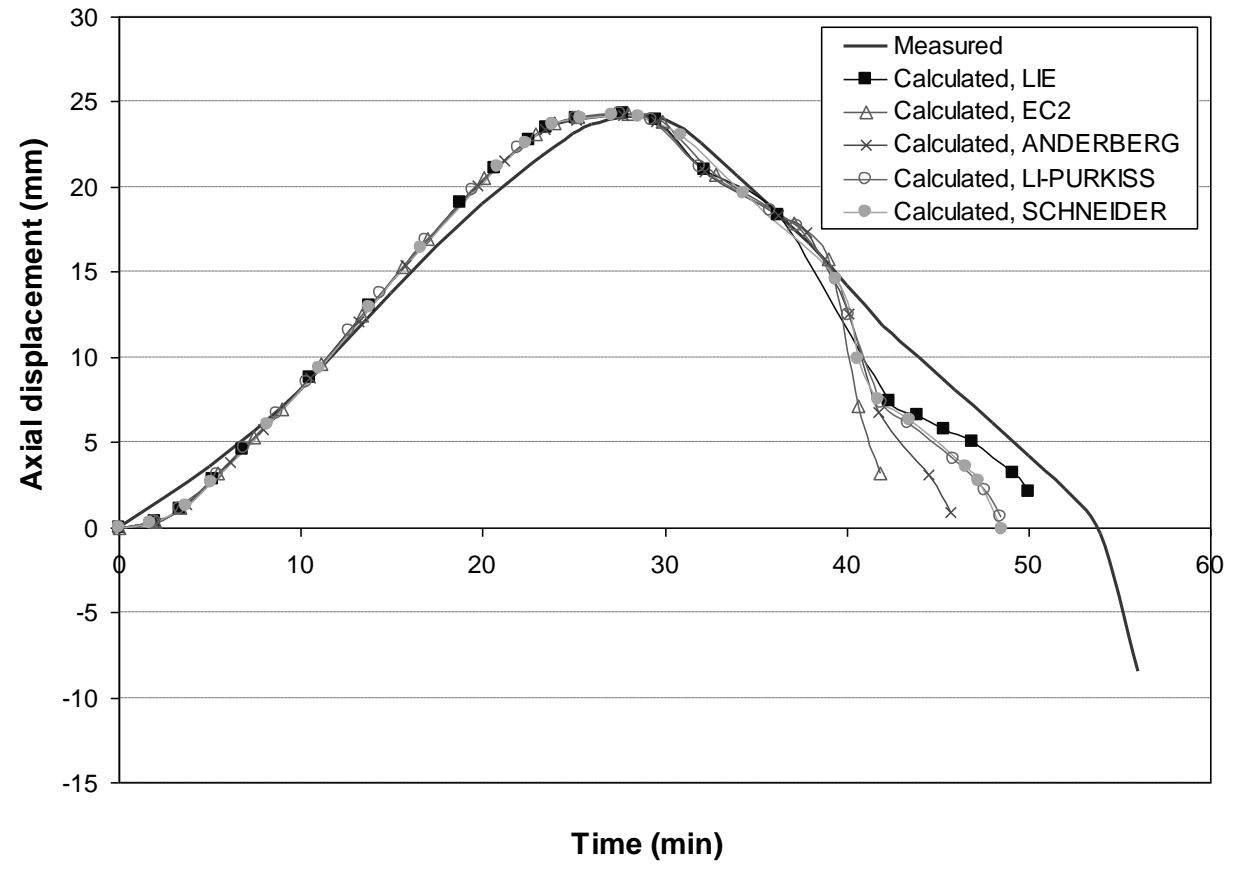

(a) Column C-04

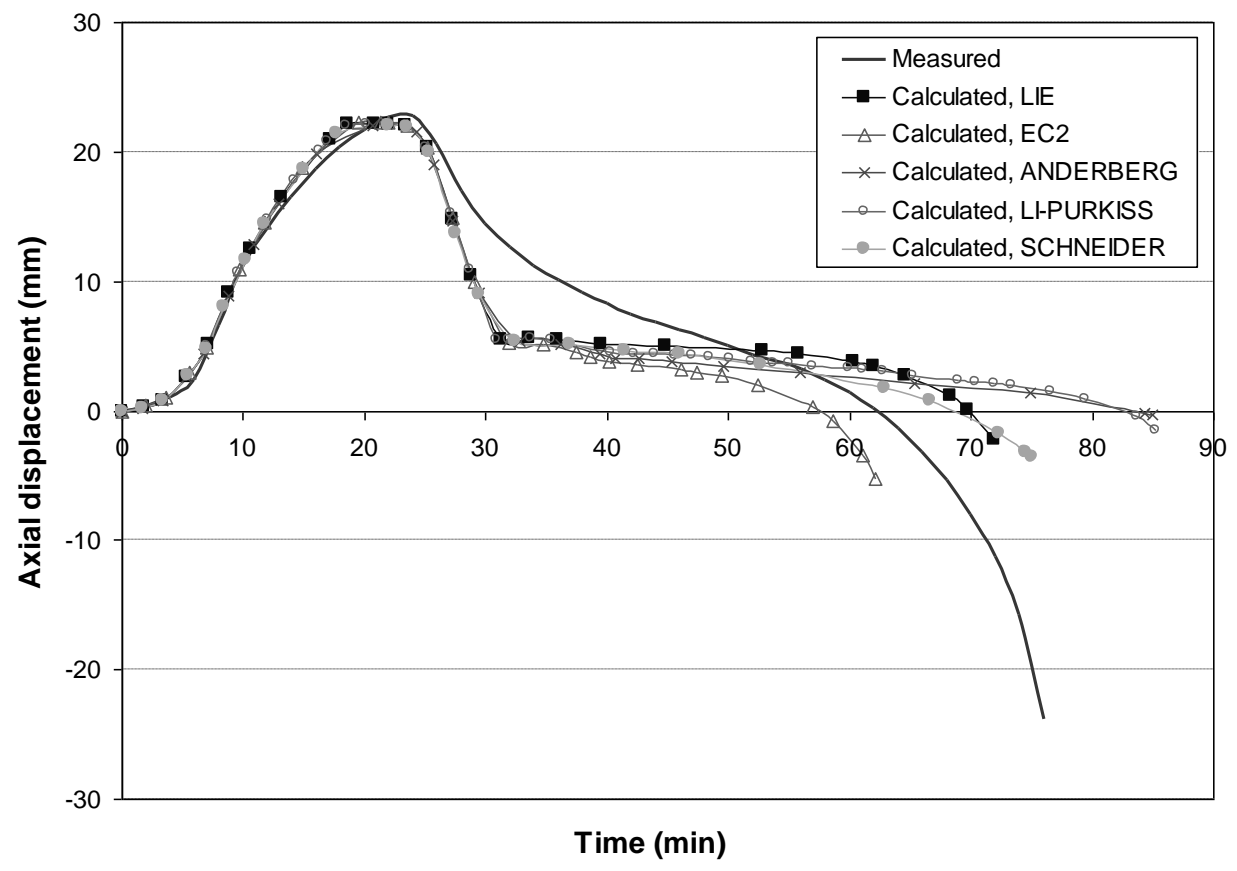

(b) Column C-05

Fig. 14. Comparison of measured and predicted axial displacement with different concrete models. 


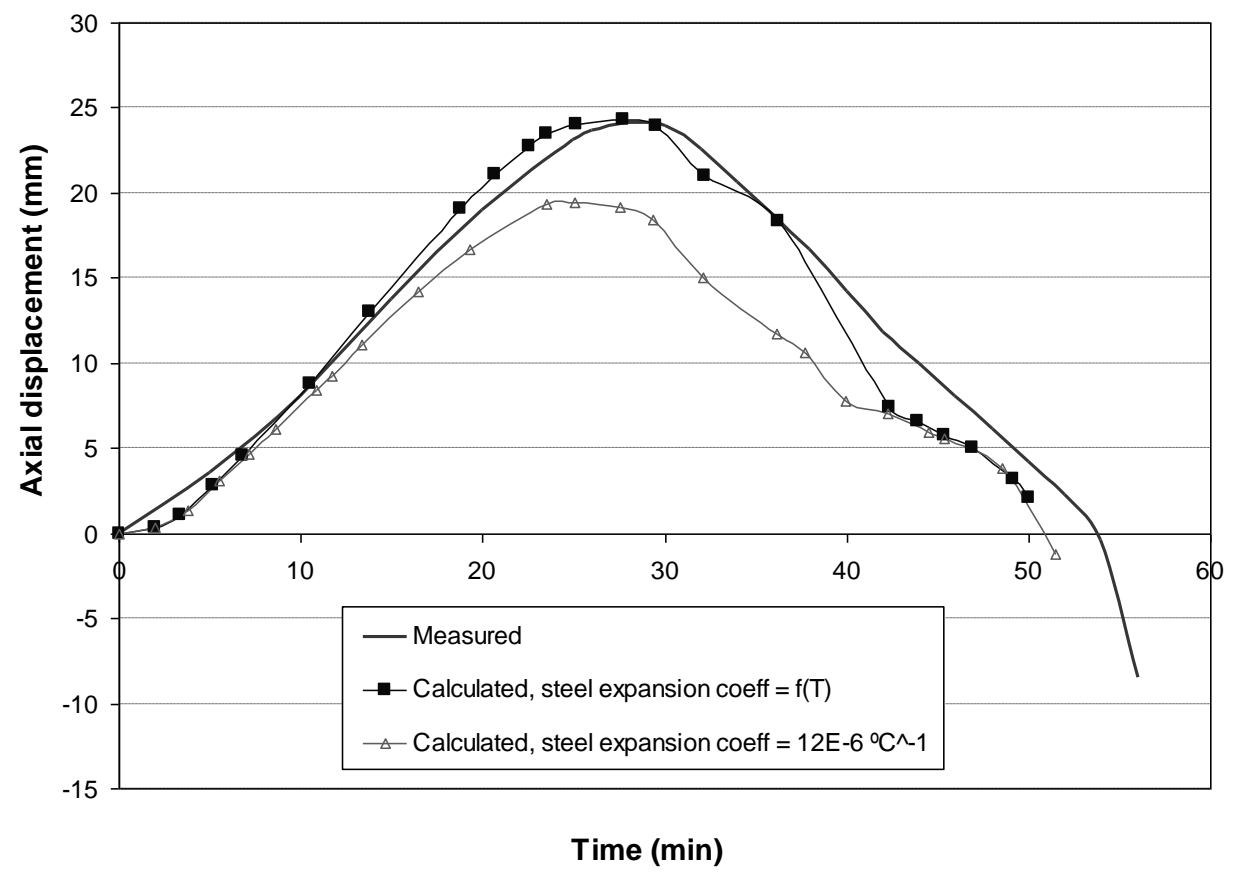

(a) Column C-04

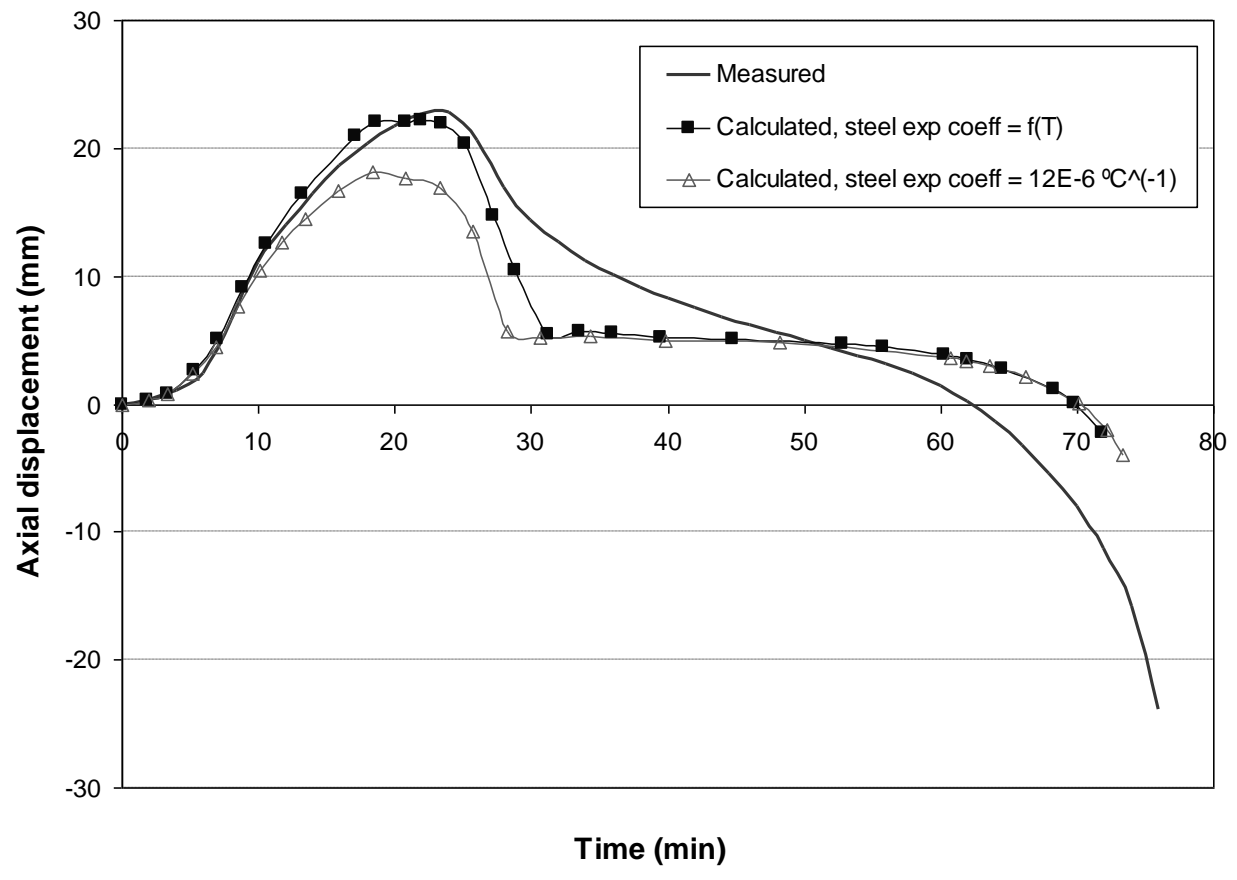

(b) Column C-05

Fig. 15. Comparison of measured and predicted axial displacement with different steel expansion models. 


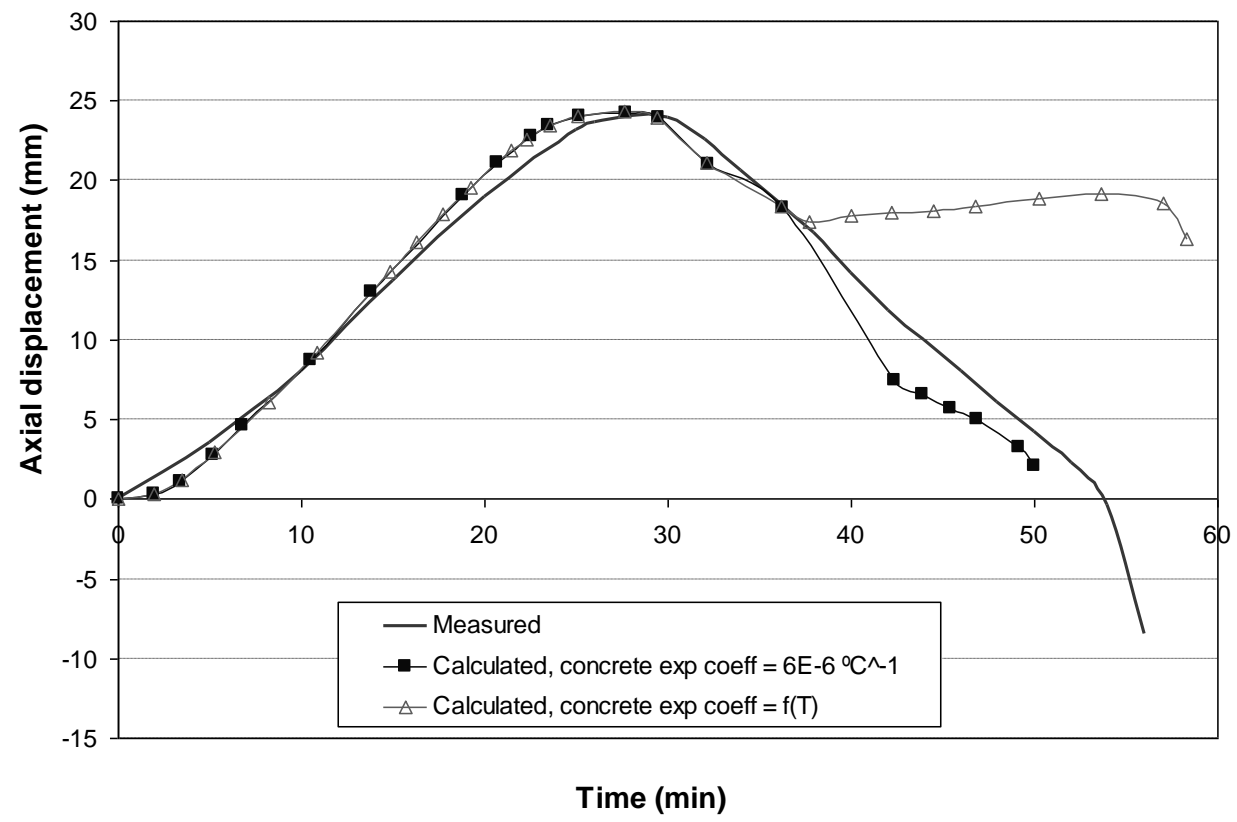

(a) Column C-04

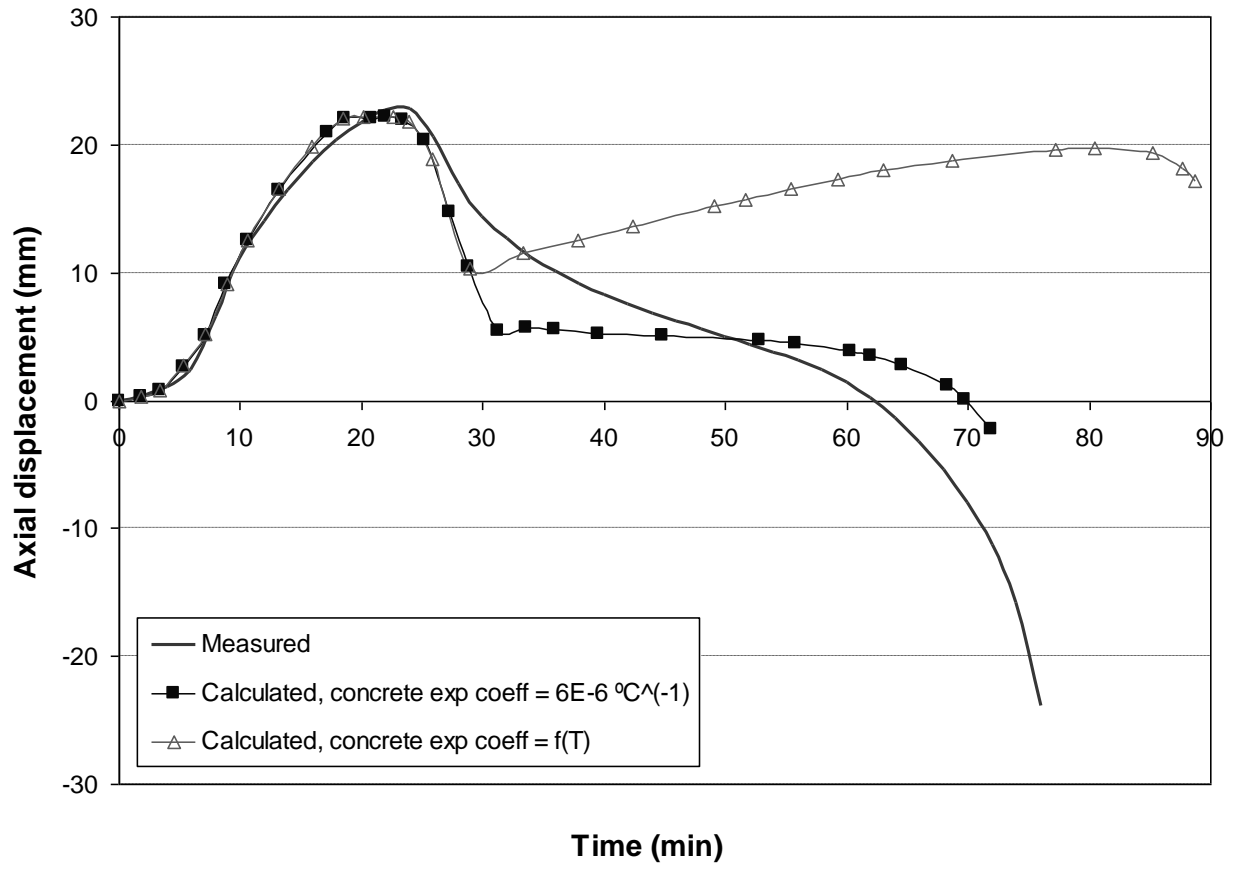

(b) Column C-05

Fig. 16. Comparison of measured and predicted axial displacement with different concrete expansion models. 


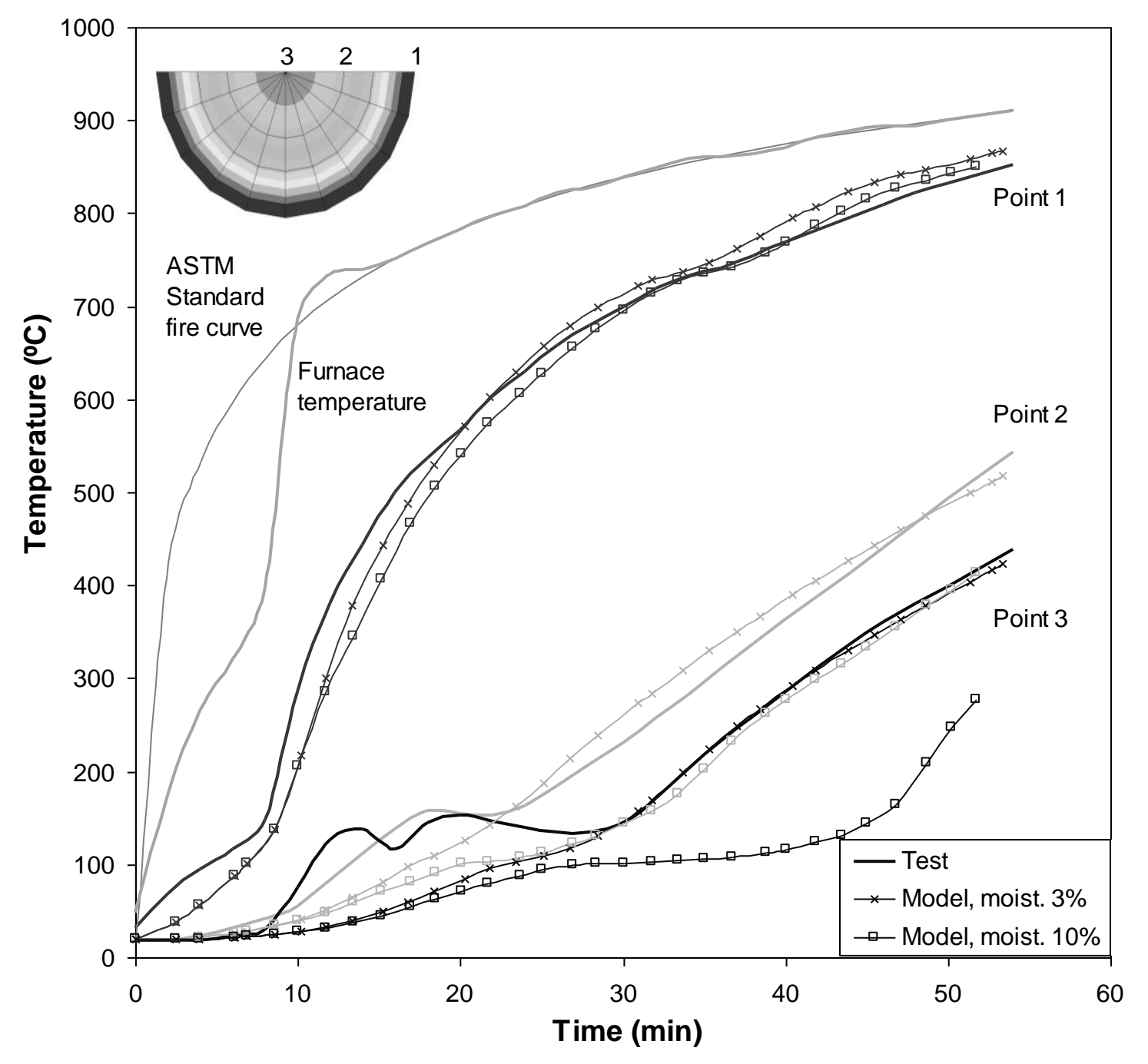

Fig. 17. Comparison between measured and predicted temperatures with different moisture values, for column C-02. 


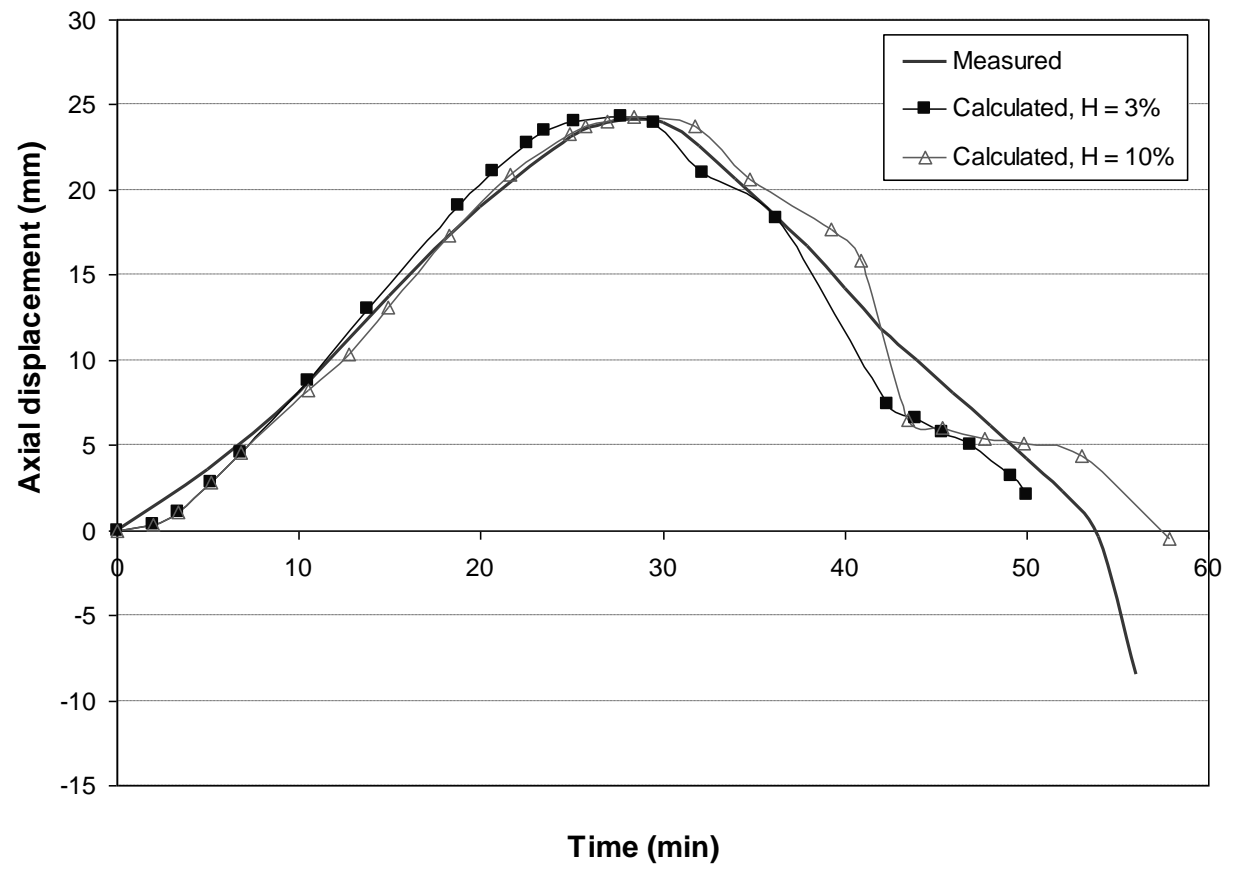

(a) Column C-04

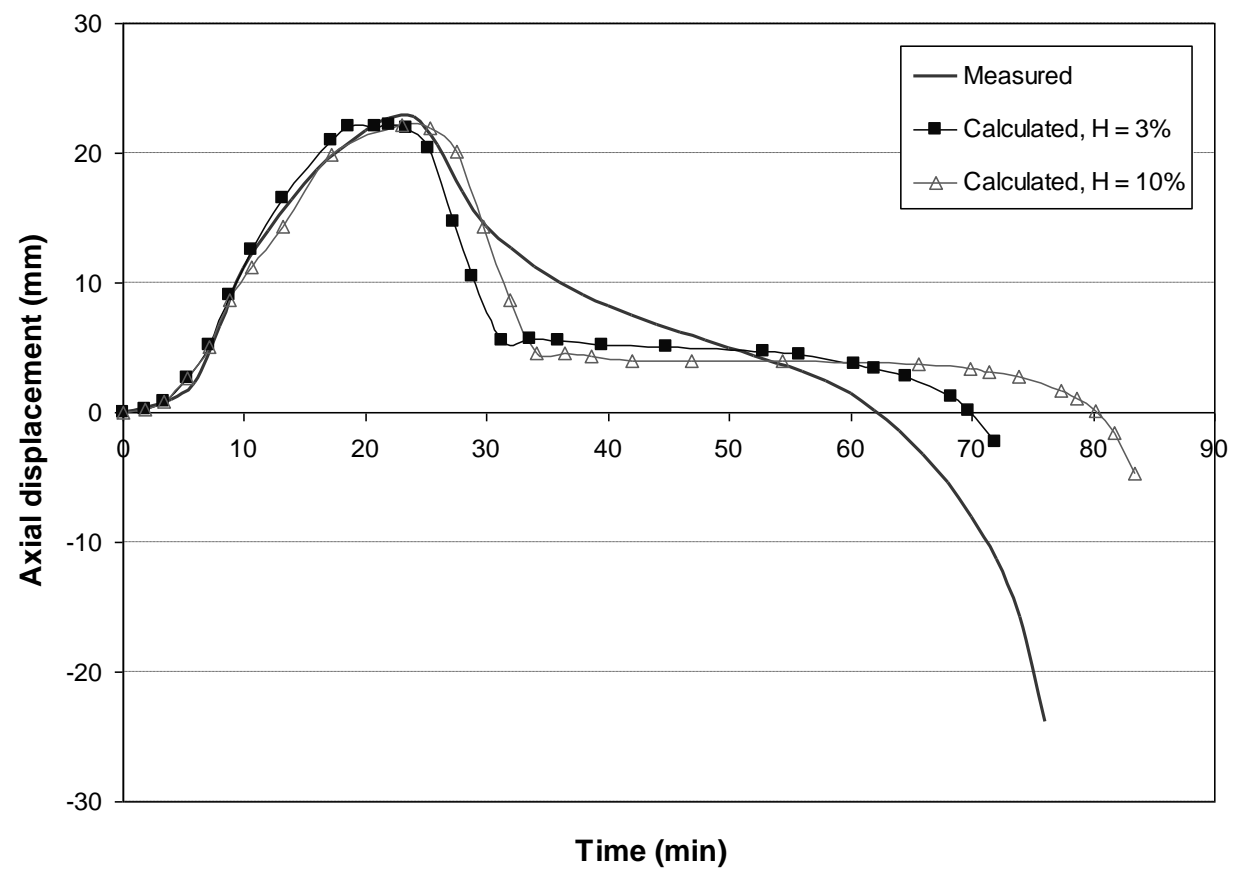

(b) Column C-05

Fig. 18. Comparison of measured and predicted axial displacement with different moisture values. 


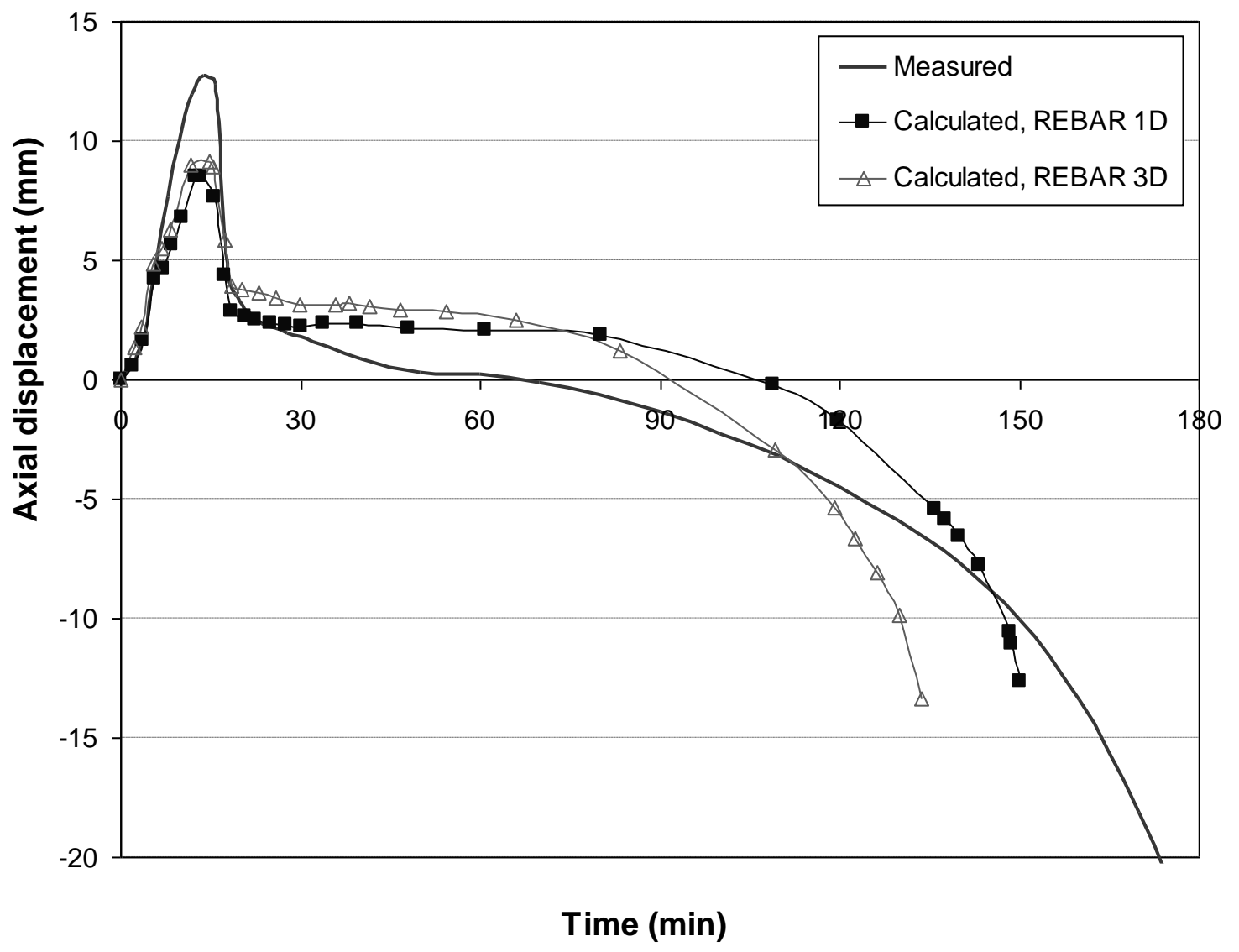

Fig. 19. Comparison of measured and predicted axial displacement with different rebar element types, for column C-48. 


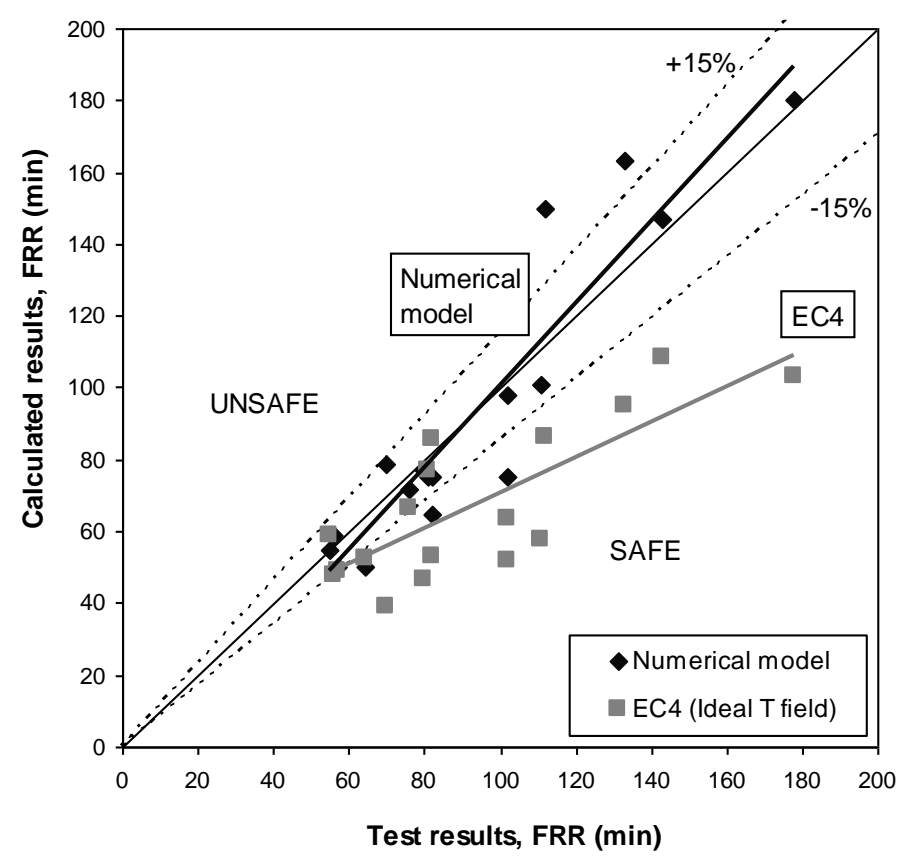

(a) Original numerical model

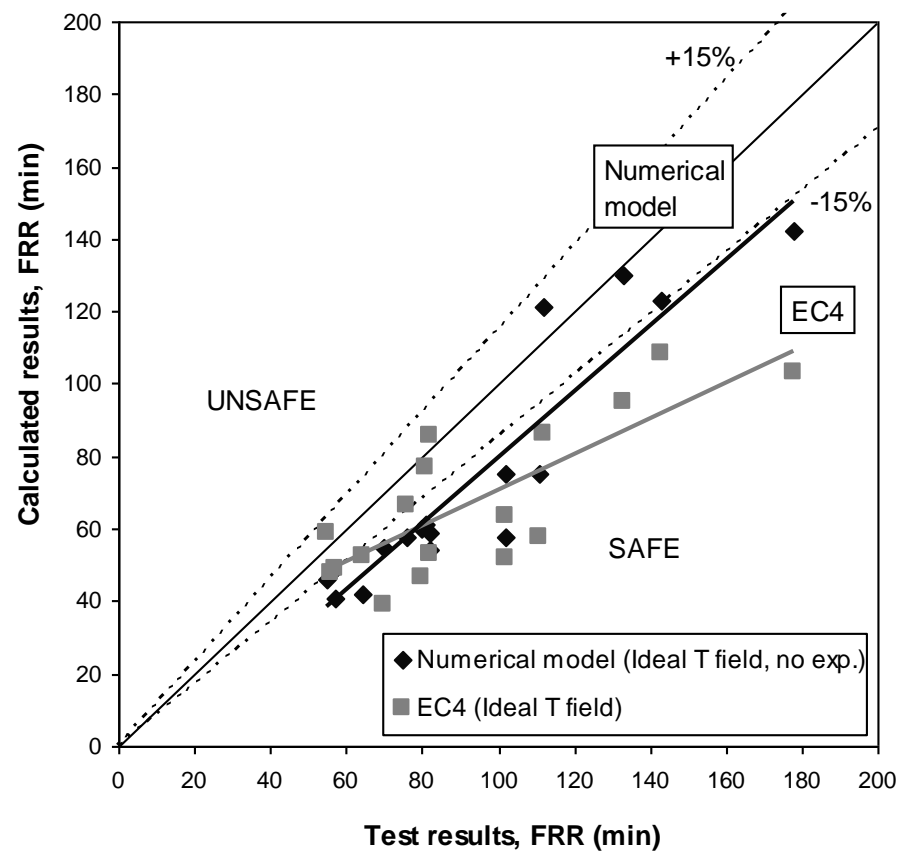

(b) Numerical model with ideal temperature field (perfect contact) and no thermal expansion

Fig. 20. Comparison of the numerical simulations (with various assumptions) and EC4 predictions with the tests. 


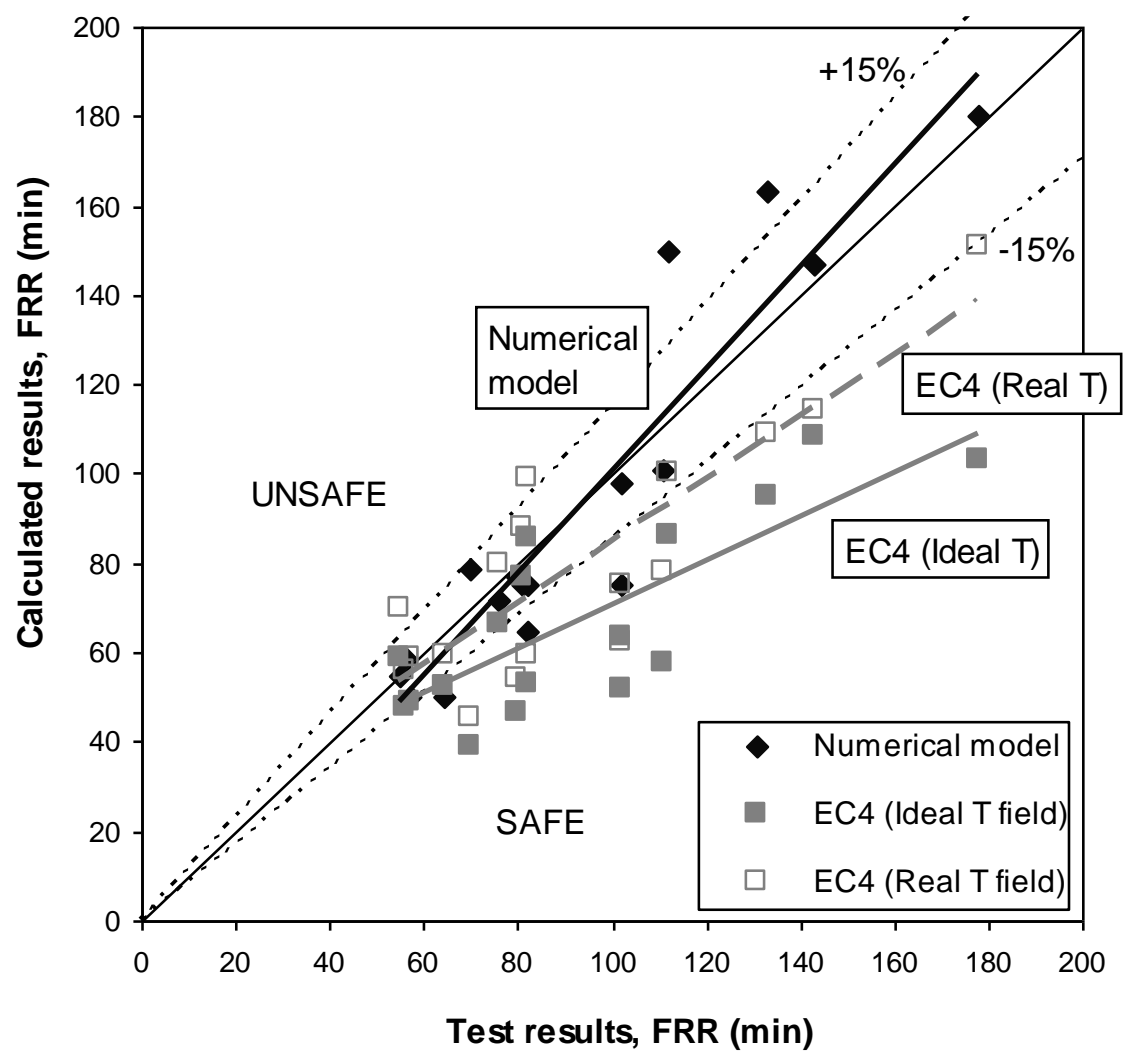

Fig. 21. Comparison of the numerical simulations and EC4 predictions with the tests, for fixed-fixed centrally loaded columns. 


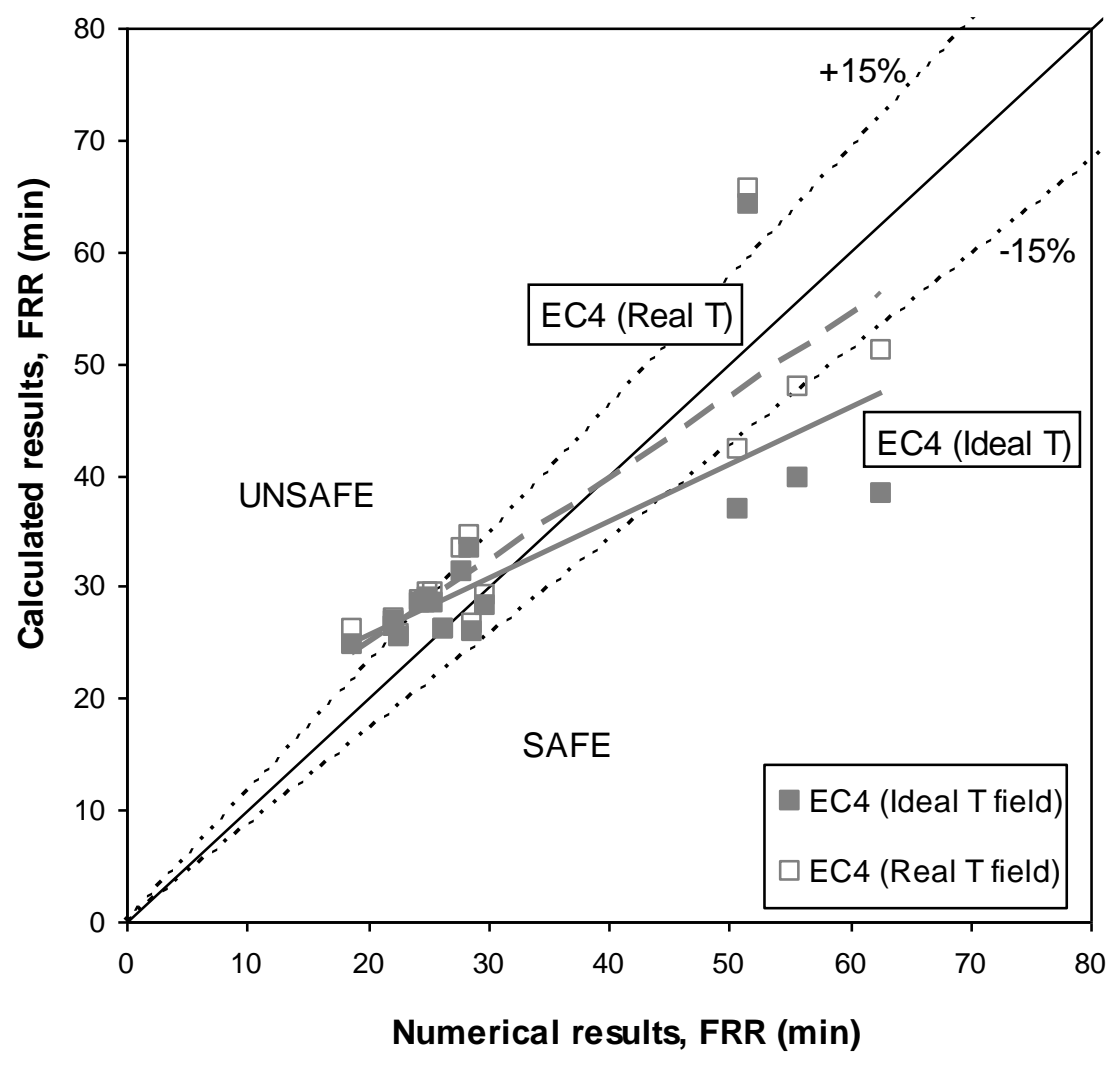

Fig. 22. Comparison of the EC4 predictions with the numerical simulations, for pinned-pinned centrally loaded columns. 


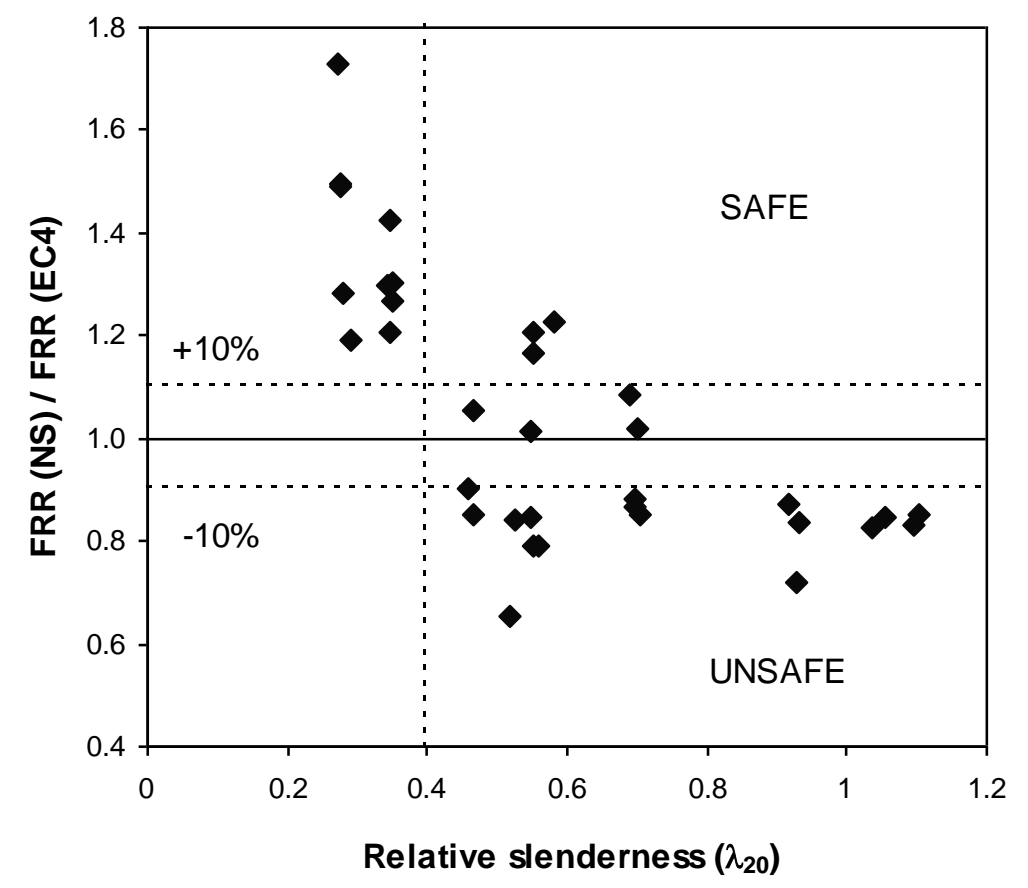

Fig. 23. Relative error of EC4 simple calculation model for different relative slenderness values. 


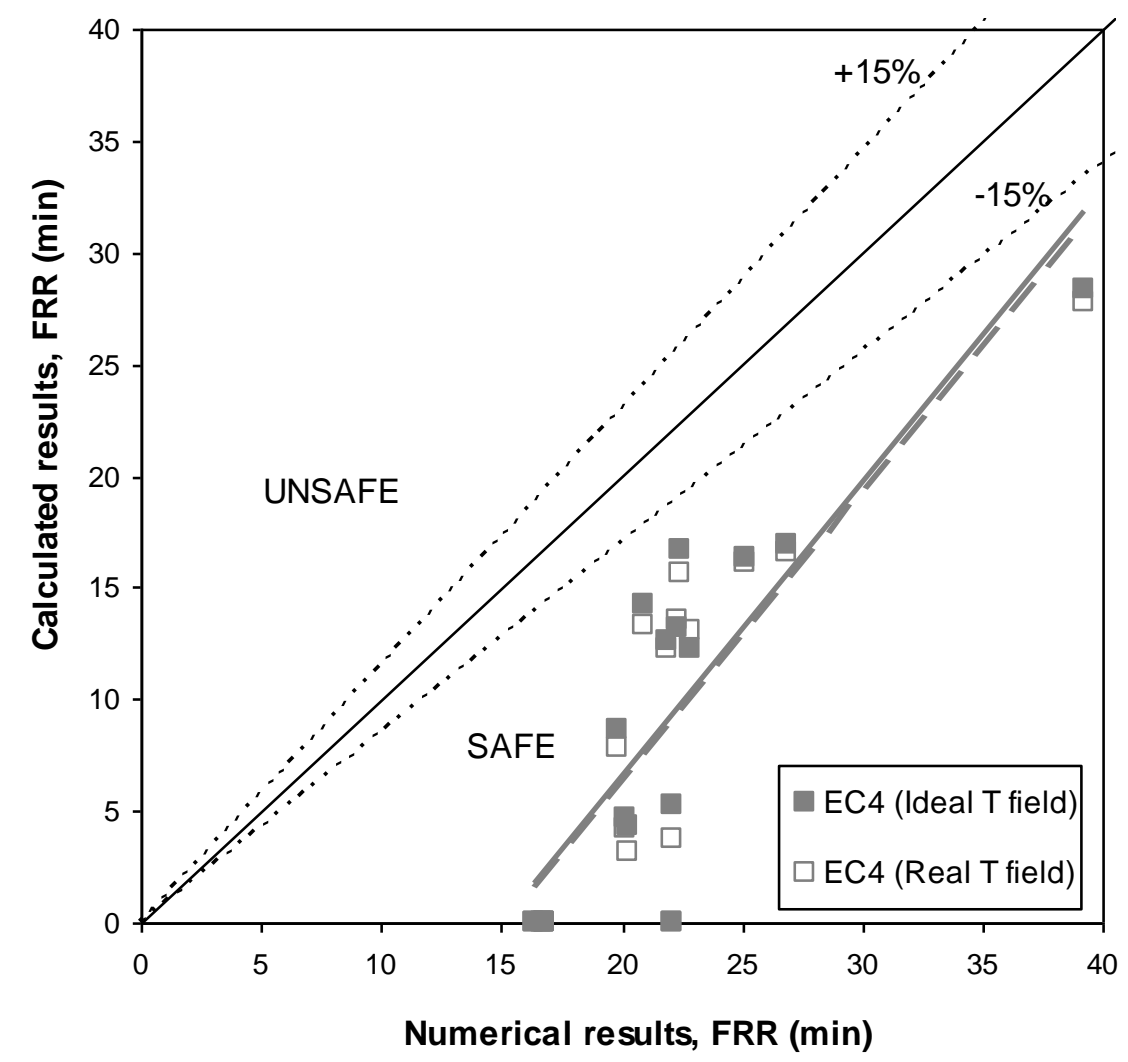

Fig. 24. Comparison of the EC4 predictions with the numerical simulations, for pinned-pinned $20 \mathrm{~mm}$ eccentrically loaded columns. 
Table 1. List of CFT columns analysed from the literature [18], $f_{c}<40 \mathrm{MPa}$

\begin{tabular}{|c|c|c|c|c|c|c|c|c|c|c|}
\hline $\begin{array}{c}\text { Column } \\
\text { No. }\end{array}$ & $\begin{array}{c}\boldsymbol{L} \\
(\mathbf{m m})\end{array}$ & $\begin{array}{c}\boldsymbol{D} \\
(\mathbf{m m})\end{array}$ & $\begin{array}{c}\boldsymbol{t} \\
(\mathbf{m m})\end{array}$ & $\begin{array}{c}\boldsymbol{f}_{\boldsymbol{y}} \\
\left(\mathbf{N} / \mathbf{m m}^{2}\right)\end{array}$ & $\begin{array}{c}\boldsymbol{f}_{\boldsymbol{c}} \\
\left(\mathbf{N} / \mathbf{m m}^{2}\right)\end{array}$ & $\begin{array}{c}\text { End } \\
\mathbf{C o n d} .\end{array}$ & $\begin{array}{c}\boldsymbol{e} \\
(\mathbf{m m})\end{array}$ & $\begin{array}{c}\boldsymbol{N} \\
(\mathbf{k N})\end{array}$ & $\boldsymbol{\mu}$ & $\begin{array}{c}\text { FRR } \\
(\mathbf{m i n})\end{array}$ \\
\hline C-02 & 3810 & 141.3 & 6.55 & 350 & $33.1(\mathrm{sil})$ & F-F & 0 & 110 & 0.12 & 55 \\
\hline C-04 & 3810 & 141.3 & 6.55 & 350 & $31.0(\mathrm{sil})$ & F-F & 0 & 131 & 0.14 & 57 \\
\hline C-05 & 3810 & 168.3 & 4.78 & 350 & $32.7(\mathrm{sil})$ & F-F & 0 & 150 & 0.16 & 76 \\
\hline C-06 & 3810 & 168.3 & 4.78 & 350 & $32.7(\mathrm{sil})$ & P-P & 0 & 150 & 0.19 & 60 \\
\hline C-08 & 3810 & 168.3 & 4.78 & 350 & $35.5(\mathrm{sil})$ & F-F & 0 & 218 & 0.23 & 56 \\
\hline C-09 & 3810 & 168.3 & 6.35 & 350 & $35.4(\mathrm{sil})$ & F-F & 0 & 150 & 0.13 & 81 \\
\hline C-11 & 3810 & 219.1 & 4.78 & 350 & $31.0(\mathrm{sil})$ & F-F & 0 & 492 & 0.35 & 80 \\
\hline C-13 & 3810 & 219.1 & 4.78 & 350 & $32.3(\mathrm{sil})$ & F-F & 0 & 384 & 0.27 & 102 \\
\hline C-15 & 3810 & 219.1 & 8.18 & 350 & $31.9(\mathrm{sil})$ & P-P & 0 & 525 & 0.28 & 73 \\
\hline C-16 & 3810 & 219.1 & 8.18 & 350 & $31.9(\mathrm{sil})$ & P-P & 34 & 525 & 0.47 & 33 \\
\hline C-17 & 3810 & 219.1 & 8.18 & 350 & $31.7(\mathrm{sil})$ & F-F & 0 & 525 & 0.26 & 82 \\
\hline C-20 & 3810 & 273.1 & 5.56 & 350 & $28.6(\mathrm{sil})$ & F-F & 0 & 574 & 0.26 & 112 \\
\hline C-21 & 3810 & 273.1 & 5.56 & 350 & $29.0(\mathrm{sil})$ & F-F & 0 & 525 & 0.23 & 133 \\
\hline C-22 & 3810 & 273.1 & 5.56 & 350 & $27.2(\mathrm{sil})$ & F-F & 0 & 1000 & 0.45 & 70 \\
\hline C-23 & 3810 & 273.1 & 12.70 & 350 & $27.4(\mathrm{sil})$ & F-F & 0 & 525 & 0.13 & 143 \\
\hline C-31 & 3810 & 141.3 & 6.55 & 300 & $30.2(\mathrm{cal})$ & F-F & 0 & 80 & 0.09 & 82 \\
\hline C-32 & 3810 & 141.3 & 6.55 & 300 & $34.8(\mathrm{cal})$ & F-F & 0 & 143 & 0.17 & 64 \\
\hline C-34 & 3810 & 219.1 & 4.78 & 300 & $35.4(\mathrm{cal})$ & F-F & 0 & 500 & 0.36 & 111 \\
\hline C-37 & 3810 & 219.1 & 8.18 & 350 & $28.7(\mathrm{cal})$ & F-F & 0 & 560 & 0.25 & 102 \\
\hline C-44 & 3810 & 273.1 & 6.35 & 350 & $38.7(\mathrm{cal})$ & F-F & 0 & 715 & 0.27 & 178 \\
\hline
\end{tabular}


Table 2. List of CFT columns analysed from the literature [9], [13], [16], [18], $f_{c}>40 \mathrm{MPa}$

\begin{tabular}{|c|c|c|c|c|c|c|c|c|c|c|c|c|}
\hline $\begin{array}{c}\text { Column } \\
\text { No. }\end{array}$ & $\begin{array}{c}L \\
(\mathbf{m m})\end{array}$ & $\begin{array}{c}D \\
(\mathbf{m m})\end{array}$ & $\begin{array}{c}t \\
(\mathbf{m m})\end{array}$ & $\begin{array}{c}\text { Rebar } \\
(\mathbf{m m})\end{array}$ & $\begin{array}{c}\boldsymbol{f}_{\boldsymbol{y}} \\
\left(\mathrm{N} / \mathbf{m m}^{2}\right)\end{array}$ & $\begin{array}{c}f_{c} \\
\left(\mathrm{~N} / \mathbf{m m}^{2}\right)\end{array}$ & $\begin{array}{c}f_{s} \\
\left(\mathbf{N} / \mathbf{m m}^{2}\right)\end{array}$ & $\begin{array}{l}\text { End } \\
\text { Cond. }\end{array}$ & $\begin{array}{c}e \\
(\mathbf{m m})\end{array}$ & $\begin{array}{c}N \\
(\mathbf{k N})\end{array}$ & $\mu$ & $\begin{array}{l}\text { FRR } \\
\text { (min) }\end{array}$ \\
\hline C-35 [18] & 3810 & 219.1 & 4.78 & - & 300 & 42.7 (cal) & - & F-F & 0 & 560 & 0.36 & 108 \\
\hline C-40 [18] & 3810 & 273.1 & 6.35 & - & 350 & 46.5 (cal) & - & F-F & 0 & 1050 & 0.37 & 106 \\
\hline C-41 [18] & 3810 & 273.1 & 6.35 & - & 350 & 50.7 (cal) & - & F-F & 0 & 1050 & 0.37 & 76 \\
\hline C-42 [18] & 3810 & 273.1 & 6.35 & - & 350 & 55.4 (cal) & - & F-F & 0 & 1050 & 0.35 & 90 \\
\hline C-48 [9] & 3810 & 273.1 & 6.35 & $4 \phi 19.5$ & 350 & 46.7 (cal) & 400 & F-F & 0 & 1050 & 0.37 & 188 \\
\hline C-49 [9] & 3810 & 273.1 & 6.35 & $4 \phi 19.5$ & 350 & 47.0 (cal) & 400 & F-F & 0 & 1900 & 0.67 & 96 \\
\hline 15C-15 [16] & 4200 & 273 & 5 & $4 \phi 18$ & 348 & $53 *$ & 475 & $\mathrm{P}-\mathrm{F}$ & 27 & 692 & 0.70 & 56 \\
\hline 77.12524A [13] & 3600 & 168.3 & 3.6 & - & 323 & 43.9 & - & F-F & 0 & 300 & 0.23 & 56 \\
\hline 77.12524B [13] & 3600 & 219.1 & 3.6 & - & 395 & 43.7 & - & $\mathrm{F}-\mathrm{F}$ & 0 & 600 & 0.26 & 45 \\
\hline $77.12524 \mathrm{D}$ [13] & 3600 & 219.1 & 3.6 & - & 385 & 43.9 & - & F-F & 0 & 600 & 0.26 & 43 \\
\hline 77.12524E [13] & 3600 & 219.1 & 3.6 & - & 400 & 43.7 & - & F-F & 0 & 300 & 0.13 & 102 \\
\hline 77.12524F [13] & 3600 & 219.1 & 3.6 & - & 400 & 43.7 & - & F-F & 0 & 900 & 0.39 & 35 \\
\hline
\end{tabular}


Table 3. Predicted and measured FRR and maximum axial displacement, $f_{c}<40 \mathrm{MPa}$

\begin{tabular}{|c|c|c|c|c|c|c|}
\hline \multirow{2}{*}{ Column No. } & \multicolumn{2}{|c|}{ FRR (min) } & \multirow{2}{*}{$\xi_{\mathrm{FRR}}=\frac{F R R_{\text {test }}}{F R R_{N S}}$} & \multicolumn{2}{|c|}{$\delta_{\max }(\mathbf{m m})$} & \multirow{2}{*}{$\xi \delta_{\max }=\frac{\delta_{\max , t e s t}}{\delta_{\max , N s}}$} \\
\hline & Test & Simulation & & Test & Simulation & \\
\hline $\mathrm{C}-02$ & 55 & 55 & 1.00 & 24.57 & 25.44 & 0.97 \\
\hline C-04 & 57 & 50 & 1.14 & 24.09 & 24.28 & 0.99 \\
\hline C-05 & 76 & 72 & 1.06 & 22.77 & 22.17 & 1.03 \\
\hline C-06 & 60 & 48 & 1.25 & 21.66 & 22.26 & 0.97 \\
\hline C-08 & 56 & 59 & 0.95 & 20.48 & 19.39 & 1.06 \\
\hline C-09 & 81 & 75 & 1.08 & 25.77 & 24.38 & 1.06 \\
\hline C-11 & 80 & 77 & 1.04 & 18.13 & 14.14 & 1.28 \\
\hline C-13 & 102 & 98 & 1.04 & 18.77 & 16.71 & 1.12 \\
\hline C-15 & 73 & 47 & 1.55 & 19.52 & 18.93 & 1.03 \\
\hline C-16 & 33 & 32 & 1.03 & 18.73 & 18.31 & 1.02 \\
\hline C-17 & 82 & 75 & 1.09 & 20.36 & 19.05 & 1.07 \\
\hline $\mathrm{C}-20$ & 112 & 150 & 0.75 & 19.44 & 15.26 & 1.27 \\
\hline C-21 & 133 & 163 & 0.82 & 20.25 & 16.05 & 1.26 \\
\hline C-22 & 70 & 79 & 0.89 & 5.51 & 7.06 & 0.78 \\
\hline $\mathrm{C}-23$ & 143 & 147 & 0.97 & 26.09 & 23.66 & 1.10 \\
\hline C-31 & 82 & 65 & 1.26 & 30.53 & 27.05 & 1.13 \\
\hline C-32 & 64 & 50 & 1.28 & 28.5 & 23.65 & 1.21 \\
\hline C-34 & 111 & 101 & 1.10 & 20.09 & 11.02 & 1.82 \\
\hline C-37 & 102 & 75 & 1.36 & 20.2 & 19.43 & 1.04 \\
\hline C-44 & 178 & 180 & 0.99 & 20.36 & 16.28 & 1.25 \\
\hline & \multicolumn{2}{|c|}{ Average } & 1.08 & \multicolumn{2}{|c|}{ Average } & 1.12 \\
\hline & \multicolumn{2}{|c|}{\begin{tabular}{|l|} 
Standard deviation \\
\end{tabular}} & 0.19 & \multicolumn{2}{|c|}{ Standard deviation } & 0.21 \\
\hline
\end{tabular}


Table 4. Predicted and measured FRR and maximum axial displacement, $f_{c}>40 \mathrm{MPa}$

\begin{tabular}{|c|c|c|c|c|c|c|}
\hline \multirow{2}{*}{ Column No. } & \multicolumn{2}{|c|}{ FRR (min) } & \multirow{2}{*}{$\xi_{\mathrm{FRR}}=\frac{F R R_{\text {test }}}{F R R_{N S}}$} & \multicolumn{2}{|c|}{$\delta_{\max }(\mathbf{m m})$} & \multirow{2}{*}{$\xi \delta_{\max }=\frac{\delta_{\max , t e s t}}{\delta_{\max , N S}}$} \\
\hline & Test & Simulation & & Test & Simulation & \\
\hline $\mathrm{C}-35$ & 108 & 104 & 1.04 & 15.59 & 8.2 & 1.90 \\
\hline C-40 & 106 & 157 & 0.68 & 15.22 & 8.73 & 1.74 \\
\hline C-41 & 76 & 165 & 0.46 & 16.05 & 8.63 & 1.86 \\
\hline C-42 & 90 & 173 & 0.52 & 14.16 & 8.47 & 1.67 \\
\hline C-48 & 188 & 174 & 1.08 & 12.7 & 8.11 & 1.57 \\
\hline C-49 & 96 & 100 & 0.96 & 1.36 & 1.95 & 0.70 \\
\hline $15 \mathrm{C}-15$ & 56 & 87 & 0.64 & 18 & 16.3 & 1.10 \\
\hline $77.12524 \mathrm{~A}$ & 56 & 47 & 1.19 & 13.7 & 13.44 & 1.02 \\
\hline $77.12524 \mathrm{~B}$ & 45 & 72 & 0.63 & 6.7 & 6.3 & 1.06 \\
\hline $77.12524 \mathrm{D}$ & 43 & 72 & 0.60 & 7.7 & 5.15 & 1.50 \\
\hline $77.12524 \mathrm{E}$ & 102 & 115 & 0.89 & 17 & 21.2 & 0.80 \\
\hline $77.12524 \mathrm{~F}$ & 35 & 49 & 0.71 & 2 & 2.15 & 0.93 \\
\hline & \multicolumn{2}{|c|}{ Average } & 0.78 & \multicolumn{2}{|c|}{ Average } & 1.32 \\
\hline & \multicolumn{2}{|c|}{ Standard deviation } & 0.24 & \multicolumn{2}{|c|}{ Standard deviation } & 0.43 \\
\hline
\end{tabular}


Table 5. Comparison of the numerical simulations (with various assumptions) and EC4 simple calculation model with the tests

\begin{tabular}{|c|c|c|c|c|c|c|c|}
\hline \multirow{2}{*}{ Column No. } & \multicolumn{5}{|c|}{ FRR (min) } & \multicolumn{3}{c|}{$\xi_{\text {FRR }}=\frac{F R R_{\text {test }}}{F R R_{\text {calc }}}$} \\
\cline { 2 - 8 } & Test & Simulation & $\begin{array}{c}\text { Simulation } \\
\text { (no expansion) }\end{array}$ & EC4 & Simulation & $\begin{array}{c}\text { Simulation } \\
\text { (no expansion) }\end{array}$ & EC4 \\
\hline C-02 & 55 & 55 & 46 & 59 & 1.00 & 1.20 & 0.93 \\
\hline C-04 & 57 & 50 & 41 & 49 & 1.14 & 1.39 & 1.16 \\
\hline C-05 & 76 & 72 & 58 & 67 & 1.06 & 1.31 & 1.14 \\
\hline C-08 & 56 & 59 & 48 & 48 & 1.25 & 1.17 & 1.18 \\
\hline C-09 & 81 & 75 & 61 & 77 & 0.95 & 1.33 & 1.05 \\
\hline C-11 & 80 & 77 & 60 & 47 & 1.08 & 1.33 & 1.71 \\
\hline C-13 & 102 & 98 & 75 & 63 & 1.04 & 1.36 & 1.61 \\
\hline C-17 & 82 & 75 & 59 & 53 & 1.04 & 1.39 & 1.54 \\
\hline C-20 & 112 & 150 & 121 & 86 & 1.55 & 0.93 & 1.30 \\
\hline C-21 & 133 & 163 & 130 & 95 & 1.03 & 1.02 & 1.40 \\
\hline C-22 & 70 & 79 & 55 & 39 & 1.09 & 1.27 & 1.79 \\
\hline C-23 & 143 & 147 & 123 & 109 & 0.75 & 1.16 & 1.32 \\
\hline C-31 & 82 & 65 & 54 & 86 & 0.82 & 1.52 & 0.96 \\
\hline C-32 & 64 & 50 & 42 & 52 & 0.89 & 1.52 & 1.22 \\
\hline C-34 & 111 & 101 & 75 & 58 & 0.97 & 1.48 & 1.93 \\
\hline C-37 & 102 & 75 & 58 & 52 & 1.26 & 1.76 & 1.97 \\
\hline C-44 & 178 & 180 & 142 & 103 & 1.28 & 1.25 & 1.73 \\
\hline
\end{tabular}


Table 6. Comparison in FRR between fire tests, numerical simulations and EC4 simple calculation model, for fixed-fixed centrally loaded columns

\begin{tabular}{|c|c|c|c|c|}
\hline Column No. & Test & $\begin{array}{c}\text { Numerical } \\
\text { model }\end{array}$ & $\begin{array}{c}\text { EC4 } \\
\text { (Ideal T field) }\end{array}$ & $\begin{array}{c}\text { EC4 } \\
\text { (Real T field) }\end{array}$ \\
\hline C-02 & 55 & 55 & 59 & 70 \\
\hline C-04 & 57 & 50 & 49 & 59 \\
\hline C-05 & 76 & 72 & 67 & 80 \\
\hline C-08 & 56 & 59 & 48 & 56 \\
\hline C-09 & 81 & 75 & 77 & 88 \\
\hline C-11 & 80 & 77 & 47 & 54 \\
\hline C-13 & 102 & 98 & 63 & 75 \\
\hline C-17 & 82 & 75 & 53 & 59 \\
\hline C-20 & 112 & 150 & 86 & 100 \\
\hline C-21 & 133 & 163 & 95 & 109 \\
\hline C-22 & 70 & 79 & 39 & 46 \\
\hline C-23 & 143 & 147 & 109 & 114 \\
\hline C-31 & 82 & 65 & 86 & 99 \\
\hline C-32 & 64 & 50 & 52 & 60 \\
\hline C-34 & 111 & 101 & 58 & 78 \\
\hline C-37 & 102 & 75 & 52 & 62 \\
\hline C-44 & 178 & 180 & 103 & 151 \\
\hline
\end{tabular}


Table 7. Comparison in FRR between numerical simulations and EC4 simple calculation model, for pinned-pinned centrally loaded columns

\begin{tabular}{|c|c|c|c|}
\hline Column No. & $\begin{array}{c}\text { Numerical } \\
\text { model }\end{array}$ & $\begin{array}{c}\text { EC4 } \\
\text { (Ideal T field) }\end{array}$ & $\begin{array}{c}\text { EC4 } \\
\text { (Real T field) }\end{array}$ \\
\hline C-02 & 24 & 28 & 29 \\
\hline C-04 & 22 & 27 & 27 \\
\hline C-05 & 26 & 28 & 29 \\
\hline C-08 & 19 & 25 & 26 \\
\hline C-09 & 28 & 31 & 33 \\
\hline C-11 & 23 & 25 & 26 \\
\hline C-13 & 30 & 28 & 29 \\
\hline C-17 & 25 & 29 & 29 \\
\hline C-20 & 51 & 37 & 42 \\
\hline C-21 & 56 & 40 & 48 \\
\hline C-22 & 26 & 26 & 26 \\
\hline C-23 & 52 & 64 & 65 \\
\hline C-31 & 29 & 33 & 35 \\
\hline C-32 & 22 & 26 & 26 \\
\hline C-34 & 29 & 26 & 27 \\
\hline C-37 & 25 & 28 & 29 \\
\hline C-44 & 63 & 38 & 51 \\
\hline
\end{tabular}


Table 8. Comparison in FRR between numerical simulations and EC4 simple calculation model, for pinned-pinned eccentrically loaded columns

\begin{tabular}{|c|c|c|c|c|c|c|}
\cline { 2 - 7 } \multicolumn{1}{c|}{} & \multicolumn{3}{c|}{$\boldsymbol{e = 2 0 ~ m m}$} & \multicolumn{3}{c|}{$\boldsymbol{e = 5 0 ~ m m}$} \\
\hline $\begin{array}{c}\text { Column } \\
\text { No. }\end{array}$ & $\begin{array}{c}\text { Numerical } \\
\text { model }\end{array}$ & $\begin{array}{c}\text { EC4 } \\
\text { (Ideal T field) }\end{array}$ & $\begin{array}{c}\text { EC4 } \\
\text { (Real T field) }\end{array}$ & $\begin{array}{c}\text { Numerical } \\
\text { model }\end{array}$ & $\begin{array}{c}\text { EC4 } \\
\text { (Ideal T field) }\end{array}$ & $\begin{array}{c}\text { EC4 } \\
\text { (Real T field) }\end{array}$ \\
\hline C-02 & 22 & 13 & 12 & 19 & 3 & 3 \\
\hline C-04 & 20 & 9 & 8 & 17 & 0 & 0 \\
\hline C-05 & 23 & 12 & 13 & 20 & 1 & 1 \\
\hline C-08 & 16 & 0 & 0 & 14 & 0 & 0 \\
\hline C-09 & 25 & 16 & 16 & 23 & 11 & 10 \\
\hline C-11 & 17 & 0 & 0 & 13 & 0 & 0 \\
\hline C-13 & 20 & 4 & 3 & 18 & 0 & 0 \\
\hline C-17 & 22 & 5 & 4 & 19 & 0 & 0 \\
\hline C-20 & 21 & 14 & 13 & 19 & 0 & 3 \\
\hline C-21 & 22 & 17 & 16 & 20 & 3 & 0 \\
\hline C-22 & 17 & 0 & 0 & 11 & 0 & 24 \\
\hline C-23 & 39 & 28 & 28 & 35 & 25 & 12 \\
\hline C-31 & 27 & 17 & 17 & 23 & 12 & 0 \\
\hline C-32 & 20 & 5 & 4 & 17 & 0 & 0 \\
\hline C-34 & 17 & 0 & 0 & 12 & 0 & 0 \\
\hline C-37 & 22 & 0 & 0 & 19 & 0 & 0 \\
\hline C-44 & 22 & 13 & 14 & 19 & 0 & \\
\hline
\end{tabular}




\section{LIST OF FIGURE CAPTIONS}

Fig. 1. Three-dimensional finite element model for CFT columns.

Fig. 2. Deformed shape after exposure to standard fire, for column C-04 [18].

Fig. 3. Comparison between measured and predicted temperatures for column C-02.

Fig. 4. Axial displacement and axial force ratio versus time, for column C-11.

Fig. 5. Comparison of measured and predicted axial displacement.

Fig. 6. Comparison of measured and predicted axial displacement with different supporting conditions, for column C-06.

Fig. 7. Comparison of fire resistance rating between calculated and test results, $f_{c}<40$ MPa.

Fig. 8. Comparison of fire resistance rating between calculated and test results, $f_{c}>40$ MPa.

Fig. 9. Comparison of measured and predicted axial displacement with different friction models.

Fig. 10. Comparison between measured and predicted temperatures with different gap conductance values, for column C-02.

Fig. 11. Comparison of measured and predicted axial displacement with different gap conductance values.

Fig. 12. Comparison of measured and predicted axial displacement with different initial imperfections.

Fig. 13. Comparison of measured and predicted axial displacement with different steel models.

Fig. 14. Comparison of measured and predicted axial displacement with different concrete models.

Fig. 15. Comparison of measured and predicted axial displacement with different steel expansion models.

Fig. 16. Comparison of measured and predicted axial displacement with different concrete expansion models.

Fig. 17. Comparison between measured and predicted temperatures with different moisture values, for column C-02.

Fig. 18. Comparison of measured and predicted axial displacement with different moisture values. 
Fig. 19. Comparison of measured and predicted axial displacement with different rebar element types, for column C-48.

Fig. 20. Comparison of the numerical simulations (with various assumptions) and EC4 predictions with the tests.

Fig. 21. Comparison of the numerical simulations and EC4 predictions with the tests, for fixed-fixed centrally loaded columns.

Fig. 22. Comparison of the EC4 predictions with the numerical simulations, for pinnedpinned centrally loaded columns.

Fig. 23. Relative error of EC4 simple calculation model for different relative slenderness values.

Fig. 24. Comparison of the EC4 predictions with the numerical simulations, for pinnedpinned $20 \mathrm{~mm}$ eccentrically loaded columns. 


\section{LIST OF TABLE CAPTIONS}

Table 1. List of CFT columns analysed from the literature [18], $f_{c}<40 \mathrm{MPa}$

Table 2. List of CFT columns analysed from the literature [9], [13], [16], [18], $f_{c}>40$ $\mathrm{MPa}$

Table 3. Predicted and measured FRR and maximum axial displacement, $f_{c}<40 \mathrm{MPa}$

Table 4. Predicted and measured FRR and maximum axial displacement, $f_{c}>40 \mathrm{MPa}$

Table 5. Comparison of the numerical simulations (with various assumptions) and EC4 simple calculation model with the tests

Table 6. Comparison in FRR between fire tests, numerical simulations and EC4 simple calculation model, for fixed-fixed centrally loaded columns

Table 7. Comparison in FRR between numerical simulations and EC4 simple calculation model, for pinned-pinned centrally loaded columns

Table 8. Comparison in FRR between numerical simulations and EC4 simple calculation model, for pinned-pinned eccentrically loaded columns 